\title{
EL DICCIONARIO DE LA ACADEMIA Y SU TIEMPO: DRAE 1817-DRAE 1852*
}

\section{THE DICTIONARY OF THE ACADEMIA AND ITS TIME: DRAE 1817-DRAE 1852}

\author{
Gloria Clavería Nadal \\ Universidad Autónoma de Barcelona \\ gloria.claveria@uab.cat
}

Recibido: $14 / 01 / 2019$

Aceptado: 15/03/2019

\begin{abstract}
Resumen
El artículo se propone establecer las principales líneas de desarrollo de seis ediciones decimonónicas consecutivas del Diccionario de la lengua castellana de la Real Academia Española, publicadas desde 1817 (5. ${ }^{\mathrm{a}}$ edición) hasta 1852 (10. ${ }^{a}$ edición), a través del análisis de los principales cambios introducidos en el proceso de enmienda de cada nueva versión de la obra. Se extraen de este examen las directrices fundamentales de la evolución de la lexicografía académica de la época y se intenta encuadrarlas en la situación histórica, social y lexicográfica en la que nacieron. Se trata de unas ediciones en las que, en su conjunto, pesa más la reducción y revisión del diccionario que la acogida de innovaciones léxicas, pues en este período esta se regía por unos criterios de admisión bastante restrictivos, en especial, en el léxico facultativo.
\end{abstract}

\begin{abstract}
The aim of this paper is to establish the main development lines of six successive editions of the Diccionario de la lengua castellana that were published in the nineteenth century, between 1817 ( $5^{\text {th }}$ edition $)$ and 1852 ( $10^{\text {th }}$ edition $)$, by the Real Academia Española through the study of the central changes that were introduced successively in the emendation process in each version. This analysis has led to prove the fundamental guidelines regarding the evolution of the academic lexicography from that time as well as framing them in the historical, social and lexicographic context in which they were conceived. As a whole, in the selected editions of the dictionary, the reduction and revision process outweighs the reception of lexical innovations in a moment when the admission criteria were rather restrictive, especially in the scientific and technical terminology.
\end{abstract}

\footnotetext{
* La investigación necesaria para llevar a cabo este trabajo ha sido posible gracias a la ayuda de la DIGICYT para el proyecto "Historia interna del Diccionario de la lengua castellana de la Real Academia Española en el siglo XIX (1817-1852)" (FFI2014-51904-P), y al apoyo del Comissionat per Universitats i Recerca de la Generalitat de Catalunya concedido al "Grupo de Lexicografía y Diacronía" (n. ${ }^{\circ}$ de referencia 2017 SGR1251).
}

Para citar este artículo / To cite this article: Clavería, Gloria (2019). El diccionario de la Real Academia y su tiempo: DRAE 1817-DRAE 1852. Azorín, Dolores; Clavería, Gloria y Jiménez Ríos, Enrique (Eds.): ELUA: El diccionario de la Academia y su tiempo: lexicografia, lengua y sociedad en la primera mitad del siglo XIX, Anexo V, págs. 13-45.

Enlace/Link: http://dx.doi.org/10.14198/ELUA2019.ANEXO5.02 
PALABRAS CLAVE: Lengua española, siglo XIX, historia de la lexicografía, Real Academia Española, diccionarios.
KEY WORDS: Spanish language, 19th century, History of Lexicography, Real Academia Española, Dictionaries

\section{INTRODUCCIÓN}

Como las obras literarias del pasado, los diccionarios son textos en los que se proyecta el mundo en el que fueron creados, al menos desde dos puntos de vista: tanto por las palabras que incluyen como por sus definiciones y equivalencias. De un modo u otro, se trasluce en estas obras el entorno en el que surgieron. Muy bien lo ha expresado J. M. Blecua (2017: 52) al observar que "la obra lexicográfica es camino, y camino cierto, para el conocimiento de mundos culturales pasados". No se debe olvidar, además, que los diccionarios suelen tener un fin ligado a la enseñanza de lenguas y a la transmisión de conocimientos por lo que su valor como objetos culturales e históricos aumenta.

Tomando como punto de partida estas ideas, si comparamos diccionarios de distintas épocas, sin duda alguna, se estarán contrastando mundos más o menos distantes; este cotejo permitirá la observación de la lengua y, por extensión, del cambio lingüístico, además de la constatación del devenir del quehacer lexicográfico, es decir, la técnica diccionarística. En este sentido, no solo es significativa la variación de la macroestructura, pues, por ejemplo, las adiciones de nuevas entradas pueden corresponder a nuevos objetos, conceptos y palabras; también lo son las variaciones en la microestructura, ya que los cambios en las definiciones, aunque de un modo más sutil, pero igualmente revelador, pueden ser testimonios tanto de los progresos científicos (Clavería, Freixas y Torruella 2019; Clavería y Paz 2018; Garriga 2019) como de los cambios socioculturales de cada época (Raab 2019). Por supuesto, no se puede ignorar el retraso con el que la innovación puede ser acogida en el diccionario, provocado por una cómoda inercia, propia de este tipo de obras (Petrecca 1992; Carriscondo 2017: 143-162). Pese a esto último, los diccionarios ofrecen un marco contrastivo inmejorable ya que su estructuración alfabética facilita el cotejo a modo de corpus paralelo, algo que se hace evidente en aplicaciones como el NTLLE o el Mapa de diccionarios (Clavería y Freixas 2018b).

El proyecto de investigación "Historia interna del Diccionario de la lengua castellana de la Real Academia Española (1817-1852)" tiene como objetivo fundamental la reconstrucción y estudio del diccionario de la Academia desde 1817 hasta 1852. La periodización aplicada (Clavería 2016, 2018a) parte de la idea de que existió un notable distanciamiento metodológico entre la cuarta edición (DRAE 1803) y la siguiente (DRAE 1817), tanto desde el punto de vista interno, el propio diccionario, como desde el externo, el marco histórico.

A principios de siglo XIX, en el año $1803^{1}$, la Real Academia Española había publicado la cuarta edición de su Diccionario de la lengua castellana; cuarta desde la primera en 1780, cuando el Diccionario de autoridades fue reducido a un "solo volumen para su más fácil uso" a costa, básicamente, de la eliminación de las citas textuales que se constituían en su

1 Para los diccionarios académicos mencionados en este estudio, se remite al NTLLE. Se citan siempre con el año de publicación, excepto en el caso de la primera edición del Diccionario de autoridades en la que se prescinde de las fechas (1726-1739). 
base empírica. En aquellos tiempos, la Academia tenía bien presente la segunda edición del Autoridades, pues el diccionario de 1780 nacía vinculado a este y, de hecho, el "reducido á un tomo para su mas fácil uso" que consta en la portada no hace más que referirse a la obra de la que procede el nuevo diccionario.

La primeras ediciones del compendio marcharon al compás del trabajo para la segunda edición del Diccionario de autoridades; así, tres años después (DRAE 1783) se publica una nueva edición del diccionario usual con algunas adiciones en las primeras letras y, en 1791, aparece la tercera, en la que se hace referencia, de nuevo, al trabajo de corrección del Diccionario de autoridades la cual llegaba, en aquel momento, hasta la letra $F$. La dependencia entre ambas obras también es perceptible en el hecho de que el resto del diccionario no tenga aumento. Al iniciarse el siglo XIX, el prólogo de la cuarta edición especifica que, por entonces, la revisión alcanzaba "hasta la L inclusive"; en esta, sin embargo, se produce una novedad con respecto a las anteriores, pues la corporación

queriendo satisfacer á las insinuaciones de muchas personas, que deseaban se pusiesen las voces que faltaban en las otras letras, ha intercalado en ellas quantas poseía, y quantas han recogido los actuales individuos de la Academia, corrigiendo asimismo algunos artículos de estas combinaciones, añadiendo además varias voces á las letras anteriores, y mejorando las definiciones de otras (DRAE 1803: prólogo).

De este modo, la cuarta edición del diccionario rompe con la progresión anterior e incluye aumento perteneciente a todo el diccionario, no solamente hasta la letra $L$. Se considera, por tanto, que la cuarta edición es la última en la que la elaboración del diccionario usual está estrechamente ligada a la revisión del Diccionario de autoridades y que se verifica un notable cambio en la edición siguiente, un cambio determinado, en gran parte, por los acontecimientos que se sucedieron en aquellos años. Hay acuerdo general entre historiadores en establecer el inicio de una nueva etapa en los primeros decenios del siglo XIX (por ejemplo, Carr 1988; Fontana y Villares 2007; Fusi y Palafox 1997), paralelamente se produce cierta ruptura con respecto a la lexicografía académica anterior a la quinta edición (Clavería y Freixas 2018a). Por todo ello, se ha tomado como punto de referencia la cuarta edición del diccionario (DRAE 1803) para analizar en profundidad las características de edición siguiente $(D R A E$ 1817) y, desde la caracterización de esta última, aplicar el cotejo entre las sucesivas ediciones del diccionario (DRAE 1817-1822, DRAE 1822-1832, DRAE 1832-1837, DRAE 1837-1843, DRAE 1843-1852) con el fin de conocer la evolución de la lexicografía académica en la primera mitad de siglo XIX. Se estima, asimismo, que, con la revitalización de la Academia a mediados de siglo XIX y la existencia de varios proyectos lexicográficos, las tres últimas ediciones del siglo (DRAE 1869-1899) deben ser estudiadas conjuntamente por lo que se ha establecido el DRAE 1852 como la fecha final de esta primera etapa (cfr. Clavería 2016).

En este artículo se pretenden compendiar las principales líneas de desarrollo del diccionario académico en las seis ediciones de la obra que ven la luz desde 1817, cuando se publica la quinta edición, hasta el año 1852, fecha de la décima edición. Se atenderá tanto a la propia historia de la obra, a través de la identificación de las transformaciones y de la idiosincrasia de cada edición, como a la interpretación de los cambios desde la reconstrucción del vínculo que se establece entre el diccionario, la corporación y la sociedad. 


\section{UNA PRIMERA APROXIMACIÓN: LAS CIFRAS DE LA ENMIENDA}

Los prólogos ponen de relieve las mejoras y novedades de cada nueva versión del diccionario (Alvar Ezquerra 2002 [1993]); frente a estos, los datos reales de la enmienda otorgan una dimensión precisa a las palabras académicas de las presentaciones. Aunque todas las ediciones suelen hacer hincapié en el aumento como una de las novedades más relevantes, las cifras de adiciones y de supresiones de entradas obtenidas en el proyecto de investigación permiten un primer acercamiento a nuestro objeto de estudio. Como se ha expuesto anteriormente, el punto de partida está constituido por el $D R A E 1803$, una obra que, según los datos extraídos del NTLLE, alberga un total de 58779 formas ${ }^{2}$. Sobre esta cifra, deben valorarse los cambios verificados en la macroestructura de cada nueva edición en términos de adiciones de formas y lemas, por un lado, y supresiones de formas y lemas ${ }^{3}$, por otro. Los resultados obtenidos figuran en los cuadros 1 y $2^{4}$.

\begin{tabular}{|c|c|c|c|c|}
\hline \multirow[t]{2}{*}{ Edición } & \multicolumn{2}{|c|}{ Adiciones } & \multicolumn{2}{|c|}{ Supresiones } \\
\hline & Formas & Lemas & Formas & Lemas \\
\hline DRAE 1817 & 1444 & 1252 & 839 & 822 \\
\hline$D R A E 1822$ & 483 & 424 & 2348 & 2323 \\
\hline DRAE 1832 & 397 & 332 & 6399 & 6395 \\
\hline DRAE 1837 & 280 & 267 & 65 & 60 \\
\hline DRAE 1843 & 542 & 530 & 135 & 130 \\
\hline DRAE 1852 & 726 & 656 & 175 & 162 \\
\hline
\end{tabular}

Cuadro 1.

2 Se trata de las formas recuperadas a través del NTLLE tanto en el diccionario (57 625) como en el suplemento (1154). Esta cifra se refiere a las formas y constituye, de momento, un material en bruto que precisa comprobaciones de diverso tipo (cfr. Clavería y Freixas 2018b). El número de entradas del diccionario es forzosamente menor por lo que se explica en la nota 3. Compárense estos datos con la cifra aproximada de 59000 entradas que proporcionaba Alvar Ezquerra (2002 [1993]: nota 55).

3 Es preciso aclarar que llamamos formas a las unidades que se proporcionan como resultado en esta aplicación y es necesario advertir que no todas ellas se corresponden con un lema o entrada porque en los diccionarios estudiados existen bastantes lemas múltiples en los que se acumulan varias formas; esto ocurre, por ejemplo, con los derivados diminutivos, agrupados frecuentemente en una sola entrada, así el lema múltiple "altarcico, cillo, cito", añadido en el DRAE 1843, es recuperado en el NTLLE a través de las tres formas que contiene (altarcico, altarcillo, altarcito). Los lemas múltiples se presentan también en otras circunstancias, por ejemplo, en variantes formales del tipo "nómade ó nómada" (DRAE 1837) o, más raramente, en formas de una misma familia morfológica, como en "brecol, lera" (DRAE 1837-1843), equivalente a las formas brecol y brecolera; también los lemas múltiples pueden estar formados por una forma simple y una compleja como en "remisoria, ó letra remisoria" (DRAE 1803-1869). Ello explica que el número de formas siempre sea superior al número de lemas o entradas. Para un tratamiento detallado de este aspecto en la quinta edición, véanse los trabajos de Freixas y Clavería (2018) y Prat (2018).

4 Es posible consultar la historia lexicográfica de cada una de las voces añadidas entre 1817 y 1852 en la aplicación Lemateca del DRAE de la página web del proyecto "Historia interna del Diccionario de la lengua castellana de la Real Academia Española en el siglo XIX (1817-1852)”, <http://draesxix.wixsite.com/draesxix>. 


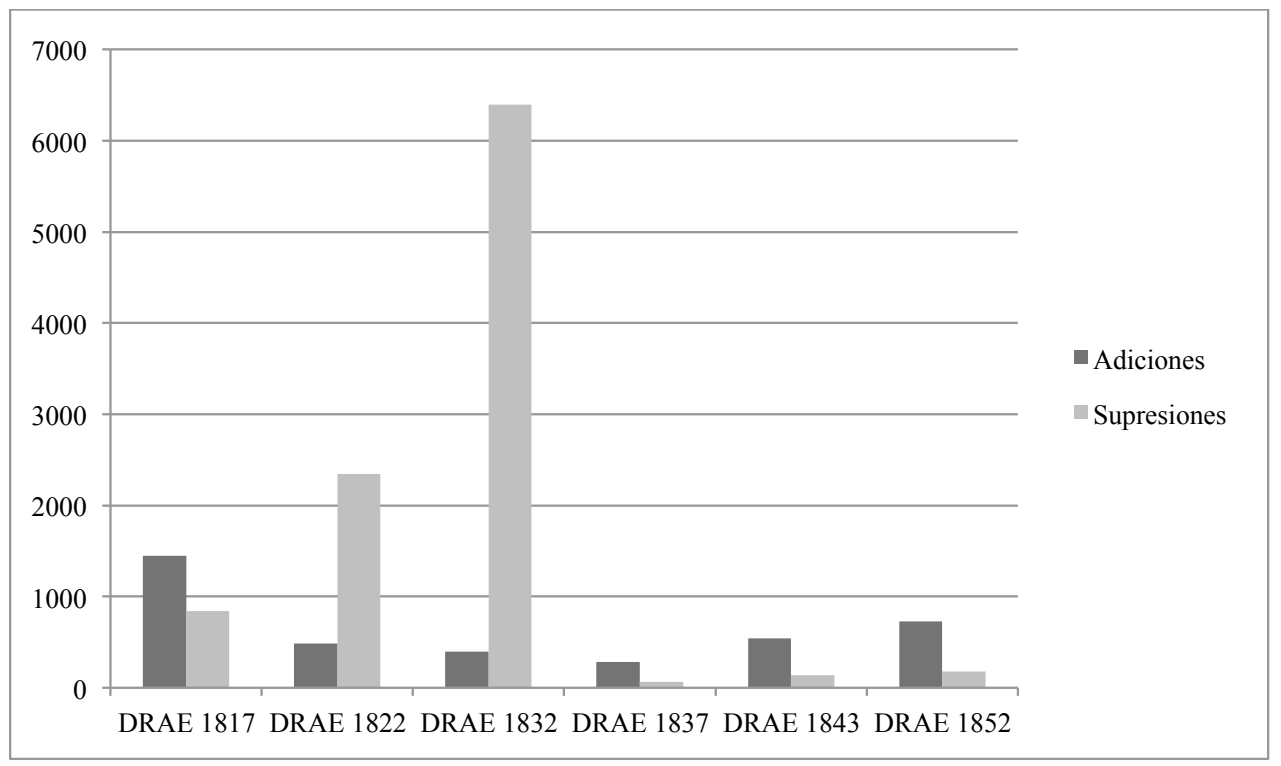

Cuadro 2.

Sobresalen en estos datos dos hechos caracterizadores de la enmienda de las ediciones estudiadas: en primer lugar, el aumento de la quinta edición es el más elevado del conjunto $\mathrm{y}$, en segundo lugar, la importancia de las supresiones de lemas en las tres primeras ediciones (DRAE 1817-1832). Globalmente en el periodo estudiado se suprimen más elementos (9961 formas) de los que se añaden (3872 formas). Los epígrafes siguientes intentarán arrojar cierta luz sobre la realidad que subyace a estos cómputos.

Permanece, sin embargo, fuera de cualquier cuantificación la ampliación de acepciones y de estructuras complejas de cada edición. Se trata de una vía de incorporación de léxico - y, en particular, de léxico especializado - muy notable que, de momento, se ha estudiado a través de calas, más o menos representativas, y mediante el cotejo manual de la microestructura entre dos ediciones ${ }^{5}$.

\section{LA QUINTA EDICIÓN DEL DICCIONARIO (DRAE 1817)}

Cuando en los primeros meses del año 1817 vieron la luz pública los seis mil ejemplares de la quinta edición del diccionario de la Academia, aquella obra lexicográfica cuyo inicio se encontraba en un lejano 1780 y como un texto dependiente de la segunda edición del Diccionario de autoridades, iniciaba un notable giro dentro de la historia lexicográfica académica.

5 Pueden leerse más detalles sobre la metodología seguida en el estudio de cada edición en Azorín et alii 2017 y Blanco, Clavería y Jiménez 2018. Utilizo en este artículo los resultados de los cotejos realizados por distintos miembros del proyecto: $D R A E$ 1817-1822 (N. Terrón y J. Torruella), DRAE 1822-1832 (E. Carriet), DRAE 18321837 (A. Paz y M. Raab), DRAE 1837-1843 (L. Muñoz y S. Varela) y DRAE 1843-1852 (J. Córdoba y N. Terrón). 


\subsection{El marco histórico y lexicográfico}

La España del siglo XIX fue especialmente convulsa y cambiante, en crisis permanente desde los primeros años de la centuria. La obra pictórica de F. de Goya permite un acercamiento de excepción a la cruda realidad de los primeros decenios del siglo a través de su penetrante mirada. La organización política del Antiguo Régimen, con el reinado de Carlos IV, muy pronto entró en crisis con el motín de Aranjuez (1808), un levantamiento popular contra la política del secretario de estado del rey, Manuel de Godoy; siguió al motín la abdicación del rey en favor de su hijo Fernando VII. Estos acontecimientos se entrelazaron con la invasión napoleónica, la consiguiente guerra de Independencia (1808-1814) y el reinado de José I Bonaparte entre 1808 y 1813. Durante la guerra, la reacción española se organizó en la Junta Central que dio lugar a las Cortes de Cádiz y la Constitución de 1812, un código jurídico que suponía una ruptura con los principios del Antiguo Régimen. Algunos académicos participaron en las Cortes (García de la Concha 2014: 154-156; Merino 2013: 82) y la Academia vivió en aquellos años momentos difíciles con lo que las labores propias de la corporación prácticamente se paralizaron (Zamora 1999: 451-455; Battaner 2008). En esta agitada situación se empezaron a producir las primeras insurgencias americanas que culminaron, años más tarde, con la emancipación de gran parte de las colonias (Lucena 1992, Bahamonde y Martínez 1994: 104 y ss.). Terminada la guerra y con la vuelta de Fernando VII en 1814, se inició una dura etapa absolutista que se prolongó hasta 1820 y, después del paréntesis liberal (1820-1823), hasta 1833, cuando muere el rey.

Desde la muerte de Pedro de Silva en 1808, la Academia permaneció sin director hasta que en marzo de 1814 ocupó el cargo Ramón Cabrera, aunque solo por unos meses. En noviembre de aquel mismo año se produjo una notable renovación de la nómina de académicos: aparte de la reposición de los miembros que habían muerto durante la guerra, algunos de ellos, al considerarse afrancesados, fueron "borrados" por orden del propio rey. De este modo, por ejemplo, Ramón Cabrera fue sustituido por el Duque de San Carlos, Miguel José de Carvajal, entonces ministro de Estado (1814) y consejero de Estado del Gobierno (18151820), quien ocupó el cargo de director hasta 1828 (García de la Concha 2014: 140-164; Clavería 2018a: 17-20).

Con el final de la guerra y el retorno de Fernando VII en la primavera de 1814, se reemprendieron las labores académicas y en tres años se publicaron, ya en 1815, la quinta edición de la Ortografía española, que recoge todos los trabajos ortográficos llevados a cabo en los años precedentes, $\mathrm{y}$, dos años después, la quinta edición del diccionario ( $D R A E$ 1817). Por tanto, la nueva edición del repertorio lexicográfico se publicó a los tres años del final de la guerra y coincidiendo con una época de gran depresión económica. La crisis había hecho mella en la Academia, lo que explica que en los primeros párrafos del prólogo de la quinta edición se mencione "la falta de fondos necesarios" para emprender la impresión de la obra y la ayuda real recibida anticipándolos, pese a que la Corona también padecía graves problemas financieros (Fontana 1971). Según los estudios realizados hasta el momento (Clavería 2016: 70-88; 2018a: 21-28), esta edición es el resultado del trabajo de enmienda del Diccionario de autoridades hasta la letra $P$, llevado a cabo de forma más o menos continuada hasta 1813, y de unas intensas labores de revisión que duraron, según el prólogo de la quinta edición, "diecisiete meses", aunque por las actas de las sesiones académicas puede observarse que se iniciaron en marzo de 1814 y se concluyeron a fines de 1816. Debió 
ser en esta última fase en la que se pudo producir la reorientación del diccionario usual, al margen de las labores del Diccionario de autoridades y en consonancia con la existencia de un proyecto de diccionario manual cuya elaboración se planteó por primera vez la Academia entre 1814 y 1816 (epígrafe 4.1.3).

Los académicos de 1817 eran conscientes de haber trabajado con prisas ante la presión de falta de ejemplares del diccionario para la venta desde $1814^{6}$, por ello se excusan en el prólogo de los posibles “defectos é inadvertencias" que la obra pudiera contener?.

\subsection{Los cambios lexicográficos}

No puede entenderse la quinta edición del diccionario fuera de las circunstancias históricas expuestas. Inicia esta obra un período de la lexicografía académica que va a prolongarse durante toda la primera mitad del siglo XIX y que se caracteriza por entrañar revisiones más o menos parciales y que, en cierta manera, vuelven la espalda a las novedades léxicas del momento. Esta forma de proceder empieza a percibirse ya en la quinta edición, y será mucho más acusada en las ediciones siguientes. La quinta edición, sin embargo, alberga algunos cambios de cierta relevancia dentro de la historia de la lexicografía.

\subsubsection{Cambios en la nomenclatura}

Aunque falta un estudio detallado de las directrices del aumento de la cuarta edición (DRAE 1803), parece percibirse en la edición siguiente un descenso en la ampliación del diccionario (cfr. Clavería 2016) que va a mantenerse hasta 1852 (cuadros 1 y 2). Destaca, además, en la quinta edición un notable número de supresiones de entradas con lo que se inaugura un tipo de enmienda que se va consagrar en las dos ediciones siguientes (DRAE 1822-1832).

Las voces añadidas pertenecen a áreas muy variadas, aunque en ellas destacan, por un lado, las palabras derivadas, pese a que en el prólogo se advierte que el aumento no solo se hace con elementos léxicos "facilmente formables", y, por otro, las voces pertenecientes a la historia natural, una de las líneas de ampliación y revisión preferentes en esta edición ${ }^{8}$.

Las supresiones de lemas son muy significativas e inician un proceso que alcanzará proporciones mucho más notables en las dos ediciones siguientes. La mitad de las formas suprimidas son lemas que el propio diccionario marcaba como anticuados (quebrantanza, suasion, certedumbre, goardar) o lemas que, aunque estaban desprovistos de esta abreviatura (ant.), se vinculaban a un lema que sí la tenía; en esta situación se encontraban los participios correspondientes a verbos portadores de la abreviatura ant. (goardado, recebido,

6 En el prólogo de la sexta edición se menciona que los ejemplares de 1803 "llegaron á tener en el comercio un valor exorbitante".

7 El propio suplemento, según el prólogo, contiene "varios artículos á que se remitían otros del cuerpo del Diccionario, y se habian omitido en sus propios lugares" y, efectivamente, esta explicación es la que permite entender la aparición de artículos como abeja machiega (citada en machiega), acacia falsa ó falsa acacia del suplemento, que son portadores de la definición que faltaba en el diccionario en la entrada acacia falsa (s. v. acacia) en la que se remitía a falsa acacia, etc.

8 Puede leerse sobre esta edición una valoración preliminar en Clavería y Freixas 2015; Clavería 2018a: 40-46. A ello se pueden añadir todos los estudios publicados en Clavería y Freixas 2018a, además del trabajo de Carriscondo (en prensa). 
etc.). Más de una tercera parte de las supresiones corresponden a meras variantes alternantes (arcaizantes o no): laberintio, laborintio, laborinto, segunt, segund, etc.

Muy posiblemente, durante el proceso de enmienda, coexisten o se suceden dos principios lexicográficos, en cierta medida, opuestos: uno, el que se había seguido y aplicado hasta entonces, bien visible en el aumento de la cuarta edición en el que cualquier variante formal era admitida en el diccionario; otro principio es el que permite explicar la supresión de estas variantes por el hecho de ser poco significativas para un diccionario de uso. Estas directrices contrapuestas conviven en esta edición del diccionario y podrían entroncar con las dos fases de elaboración a las que se ha hecho referencia anteriormente (hasta $1813 \mathrm{y}$ después de 1814). En las dos ediciones siguientes, sin embargo, se opta por la supresión de muchas variantes formales con lo que se produce una relevante modificación en los criterios lexicológicos y lexicográficos aplicados en la configuración de la obra académica.

\subsubsection{Los cambios en la microestructura}

Varias son las transformaciones vinculadas con la metodología lexicográfica que se introdujeron en el diccionario de 1817 por lo que el valor de esta edición dentro de la historia de la lexicografía es más que notable. Quizá el más destacado se encuentre en los principios de ordenación de las estructuras complejas: si hasta entonces se habían seguido criterios poco concretos para incluirlas en un lema u otro - se seleccionaba la palabra "con más alma ó fuerza", según el prólogo del DRAE 1817—, a partir de la quinta edición se utilizan criterios gramaticales basados en la jerarquización de las categorías que forman la locución (sustantivo, verbo, adjetivo). Se trata de un avance lexicográfico que implicó una reestructuración completa del diccionario con la reubicación de las estructuras complejas y que, a buen seguro, comportó “deshacer" la edición de 1803 y volverla a disponer siguiendo los nuevos principios establecidos para la quinta edición (Buenafuentes 2018, Paz 2018).

También desde una perspectiva metalexicográfica se verifican cambios en las abreviaturas de notación diacrónica y estilística. En estos aspectos se imponen reformas que tienden a la simplificación de la notación empleada hasta entonces con la supresión de ciertas abreviaturas. Así, en el caso de la información de la vigencia de uso, el diccionario, desde 1780 hasta 1803, utilizó las abreviaturas ant. (anticuado), p. us. (poco usado) y r. (raro), y en la quinta edición fueron unificadas en favor de la primera (Jiménez Ríos 2018c). Del mismo modo, en el caso de las abreviaturas de carácter estilístico, el diccionario empleó distinciones entre familiar (fam.), bajo (bax.), festivo (fest.), jocoso (joc.) y vulgar (vulg.) desde 1780 hasta 1803; a partir de la quinta edición, todas ellas fueron aunadas en favor de la primera (Azorín 2018a).

La preocupación por la exactitud de la definición es constante en la lexicografía académica y se descubre en la quinta edición una amplia enmienda en ella, al menos en dos aspectos distintos: por un lado, aparece una abundante reescritura de las definiciones en un intento de mejora permanente; por otro, se verifica la revisión sistemática de las definiciones de las voces pertenecientes a la historia natural. Ambas intervenciones quedan claramente recogidas en el prólogo.

La reescritura de las definiciones comportó prescindir de aquella información que se consideró superflua y que, en algunos casos, se remontaba al enciclopedismo tan característico del Diccionario de autoridades. Buena ilustración se halla en los cambios registrados 
en la voz abada (Freixas 2018: 168), en los que puede observarse la desaparición de gran parte de los datos históricos, un tipo de información que había sido incluida en la segunda edición del Diccionario de autoridades y que se mantiene hasta el DRAE $1803^{\circ}$. Cabe recordar que la resonancia de la abada regalada al rey en el Madrid del milquinientos fue enorme como demuestra su aparición en varios textos (cfr. Chaffee-Sorace 1988: 26 y ss. y DECH, s. v. $a b a d a)$ y su incorporación es muestra del afán por integrar el mundo del pasado en el diccionario (cuadro 3).

\begin{tabular}{|c|c|c|}
\hline Diccionario de autoridades 1770-DRAE 1803 & DRAE 1817 & DRAE 1822 \\
\hline $\begin{array}{l}\text { ABADA. s. f. Lo mismo que RINOCERONTE. El nombre } \\
\text { de ABADA le dieron los Portugueses á este animal al } \\
\text { tiempo de sus conquistas en el Oriente: y como la } \\
\text { lengua portuguesa se hizo casi general en los puertos } \\
\text { y escalas de la India, los escritores viageros que oían } \\
\text { llamar así al rinoceronte, aun á los mismos naturales, } \\
\text { creyéron fuese voz indiana, y diéron motivo á que este } \\
\text { error corra impreso en muchos libros de Europa, lo } \\
\text { que tambien ha sucedido con otras voces portuguesas. } \\
\text { En el reynado de Felipe II. año de } 1581 \text {. vino una } \\
\text { ABADA á Madrid con un elefante que envió de regalo } \\
\text { el Gobernador de Java, y dexó perpetuada su memoria } \\
\text { comunicando su nombre á la calle en que estuvo, que } \\
\text { hasta hoy llamamos de la Abada. Y esta misma sin } \\
\text { duda es la que se halla dibuxada en la obra de JUAN } \\
\text { DE ARFE de varia conmesuracion. lib. } 3 \text {. cap. } 3 \text {. pág. } 8 \text {. } \\
\text { pues advierte que no dibuxó otros animales que los que } \\
\text { vió vivos. }\end{array}$ & $\begin{array}{l}\text { ABADA. s. f. Lo mismo } \\
\text { que RINOCERONTE. El } \\
\text { nombre de ABADA le } \\
\text { dieron los portugueses } \\
\text { á este animal al tiempo } \\
\text { de sus conquistas en el } \\
\text { Oriente. }\end{array}$ & $\begin{array}{l}\text { ABADA. s. f. } \\
\text { RINOCERONTE. }\end{array}$ \\
\hline
\end{tabular}

Cuadro 3.

En el ejemplo puede apreciarse el itinerario que sigue la información lexicográfica determinado por la equivalencia inicial entre abada y rinoceronte. Se observa la superposición de diversas fases de enmienda surgidas de las distintas ediciones del diccionario: si en la quinta edición y, siguiendo el postulado de la supresión de "muchas palabras y expresiones redundantes, y varias noticias y etimologías que han parecido poco necesarias y oportunas", se elimina gran parte de las noticias históricas ligadas al Diccionario de autoridades, en la edición siguiente la información queda reducida a una simple remisión. La exclusión de datos enciclopédicos, por considerarse no pertinentes, lleva a la pérdida de una parte del mundo que se reflejó en las primeras versiones de la obra. Se manifiesta, además, en esta evolución el progresivo avance hacia la formalización de las relaciones semánticas con la implantación de la definición en la palabra más común y la remisión en las menos frecuentes o de uso restringido. Ya los académicos de 1817 eran plenamente conscientes de que el

9 Se percibe en esta información el eco del Tesoro de Covarrubias (s. v. abada) a cuya autoridad se apela en la entrada bada para expresar la preferencia por la forma abada frente a la variante bada. El Diccionario de autoridades de 1770 incluía, además, tres autoridades que, como es natural, desaparecieron en la edición de 1780. 
diccionario albergaba no pocas inconsistencias en el sistema de remisiones (DRAE 1817: prólogo) $\mathrm{y}$, aunque intentaron corregir esta deficiencia, no siempre lograron resolver los desajustes existentes y, aún, crearon nuevas incoherencias (Gómez de Enterría 2018: 303-305; Muñoz 2018), cuya corrección se extiende a las dos ediciones siguientes.

También la reescritura de la definición es claramente perceptible en las voces de especialidad: en estas, las modificaciones entrañan una remodelación según conocimientos especializados más o menos actualizados. Es este uno de los aspectos más interesantes de la quinta edición porque evidencia la voluntad de proyectar en el diccionario aquellos "adelantamientos de estos últimos tiempos" que habían "aclarado y corregido diferentes equivocaciones que antes eran comunes", mencionados en el prólogo y referidos al avance científico conseguido en la última Ilustración. Destaca la labor realizada en dos áreas del saber muy importantes en la época: las ciencias naturales y la química. En ambas disciplinas se habían producido en el siglo XVIII y bajo los auspicios de los Borbones grandes progresos y estos, con mayor o menor éxito, afloran en la nomenclatura y en las definiciones de la quinta edición reflejando la voluntad de adecuación científica del diccionario (Gómez de Enterría 2018 y Garriga 2018).

Cabe tener en cuenta, asimismo, que la quinta edición comportó un examen extenso e intenso de las correspondencias latinas (Jiménez Ríos y Clavería 2018). El gran esfuerzo dedicado a esta área se manifiesta en el hecho de que casi cada equivalencia fuera enmendada, amén del elevado número de acepciones a las que se añadió el correlato latino.

\section{LA CONSAGRACIÓN DE UN NUEVO MODELO DE DICCIONARIO: DRAE 1822 Y 1832}

El "pronto despacho de los seis mil ejemplares de la quinta edición" (DRAE 1822: prólogo) explica que justo cinco años después se publicase la siguiente en un ambiente político y social completamente distinto, el trienio constitucional (1820-1823), de modo que en el pie de imprenta de la sexta edición figura la "Imprenta Nacional" y no "Imprenta Real" como ocurría en la edición precedente. También entonces se solicitó la reincorporación de R. Cabrera (Zamora Vicente 1999: 179), quien participó activamente en la enmienda de la séptima edición remitiendo listas de voces, artículos y correcciones (Actas, 1826-1829).

La nueva versión del diccionario se reconoce continuadora de las directrices lexicológicas y lexicográficas de la edición anterior, pero, desde las primeras líneas del prólogo, se hace alusión a "la supresion de algunas fórmulas y artículos" llevadas a cabo "sin perjuicio de la claridad conveniente y con mucho ahorro de palabras", algo que se constituye en su verdadero fundamento. Efectivamente, los datos del aumento y de las supresiones de entradas confirman estas palabras, pues mientras que solo se incorporan 424 lemas (483 formas), se suprimen 2323 lemas (2348 formas), con lo que la cifra de estos últimos es muy superior a la primera. La razón de este modo de proceder se encuentra en el "ahorro de palabras" mencionado anteriormente y este objetivo se consigue tanto con las supresiones de artículos, ya iniciado en la edición precedente, como con diversas modificaciones de la microestructura que también tienden a la economía.

Algo semejante ocurre en la séptima edición, la cual ve la luz pública diez años después de la sexta, a principios de 1832, el año anterior a la muerte de Fernando VII. El ínterin entre estas dos ediciones se corresponde con la nueva etapa absolutista (1823-1833), en medio de una represión que "golpeó sobre todo a políticos y hombres de letras, oficiales del Ejército, 
funcionarios de la Administración y eclesiásticos liberales" (Fusi y Palafox 1997: 35), algo que afectó de pleno a la vida cotidiana de la corporación, pues ni hubo reposición de académicos ni se celebraron las juntas con normalidad (Ferrer del Río 1870 [1860]: 192-193; Roca de Togores 1870: 31 y ss.; Zamora 1999: 455; García de la Concha 2014: 177-179).

Las adiciones de lemas de la séptima edición alcanzan la exigua cifra de 332 lemas (397 formas) mientras que las supresiones ascienden a 6395 lemas (6399 formas). El prólogo de la séptima edición hace referencia a este aspecto de la enmienda, pues expone que uno de los objetivos ha sido "facilitar su uso a los lectores" mendiante un plan que "lleva adelante las supresiones hechas en la anterior, y añade ciertas innovaciones, que debiendo disminuir su volumen, la hacen todavía mas manejable", porque el objetivo de la séptima edición fue justamente este. Con estas reformas, estas dos ediciones consiguieron que el diccionario ocupara unas ciento treinta páginas menos.

\subsection{Las reducciones de la sexta y la séptima edición}

Estas dos versiones del diccionario, por tanto, entrañan la eliminación de un buen número de entradas y en los dos casos las supresiones de lemas superan con creces las adiciones. Los artículos excluidos en cada una de las ediciones son sustancialmente diferentes, por lo que se puede decir que se trata de intervenciones parcialmente distintas. Además, cada una de las dos ediciones introdujo otros cambios con la misma orientación. De todo ello, surge un nuevo modelo de diccionario y, por extensión, un nuevo modelo de lexicografía académica.

\subsubsection{DRAE 1822}

Como se ha expuesto anteriormente, el prólogo de la sexta edición se refiere a la "supresion de algunas fórmulas y artículos". Es decir, el "ahorro de palabras" se lleva a cabo de dos modos distintos: por un lado, con la eliminación de algunas expresiones empleadas en el discurso lexicográfico que establecían relaciones de carácter paradigmático y, por otro, con la supresión de cierto tipo de entradas.

En el caso de las "fórmulas" se cita específicamente en el prólogo que se prescinde de "lo mismo que", expresión empleada en las remisiones y, al igual que se había indicado en el prólogo de la quinta edición, se advierte que se pone especial cuidado en la revisión de las remisiones. Las directrices que siguió esta enmienda pueden encontrarse en la investigación llevada a cabo por Terrón y Torruella (2019b). También se prescindió de otras notaciones que indicaban la frecuencia de uso a la vez que establecían relaciones paradigmáticas entre palabras sinónimas, así en el prólogo se reconoce:

Igual economía ha tenido en las expresiones: que es como mas comunmente se dice; que es mas usado; que se usa mas frecuentemente; y otras semejantes; pues solo la remisión de una voz á otra, que está definida, basta para indicar que esta es la mas propia de un uso mas comun y constante (DRAE 1822: prólogo).

Además, un cotejo detallado de la microestructura de la sexta edición con respecto a la inmediatamente anterior revela una tendencia al acortamiento de las definiciones a través de la supresión de ciertas palabras y expresiones que se juzgaron prescindibles (cierto, especie 
de); se reduce, asimismo, la información enciclopédica, en especial, en las voces pertenecientes a las ciencias naturales, aunque no fueron las únicas que experimentaron cambios (Terrón y Torruella 2019a: epígrafe 4.2).

Tal como se demuestra en diversos estudios relacionados con el proyecto de investigación "Historia interna del Diccionario de la lengua castellana de la Real Academia Española en el siglo XIX (1817-1852)", la gran mayoría de lemas eliminados en la sexta edición son voces anticuadas, portadoras de la abreviatura ant. Este tipo de lemas constituye el $80 \%$ de la supresión (Terrón y Torruella 2019a) y suelen ser variantes antiguas y sinónimas de otras formas en uso: egual frente igual, abat frente a abad, etc. (cfr. Jiménez Ríos 2018b y 2019; Clavería, en prensa 1).

Aparece en este tipo de supresiones la aplicación de una concepción que entronca con la lingüística histórica y que es claramente expresada en el prólogo de esta edición al señalar que "los diversos estados de pronunciacion y ortografia que padece una voz desde que sale de una lengua madre, de la latina por ejemplo hasta que se fija en un idioma vulgar como el castellano, no deben mirarse como palabras diversas" (DRAE 1822: prólogo). Esta nueva consideración de la oposición entre palabra y variante, y su reflejo en el diccionario explica que muchas entradas que se habían incorporado en el $D R A E 1803$ fueran suprimidas en las dos ediciones siguientes ${ }^{10}$; con ello, puede comprobarse la modificación de los fundamentos lexicográficos del diccionario operada en los primeros decenios del siglo XIX.

\subsubsection{DRAE 1832}

En esta edición el decrecimiento del diccionario se consigue, en la nomenclatura, con la eliminación de entradas y, en la microestructura, con la aplicación de actuaciones diversas. En el caso de estas últimas, se verifican las modificaciones siguientes:

En primer lugar, se introduce una notable mudanza en la estructura del artículo lexicográfico con la supresión de las entradillas y la disposición de las distintas acepciones y locuciones seguidas y separadas por la doble pleca ${ }^{11}$. Este sistema comporta la eliminación de la repetición del lema en cada una de las entradillas; asimismo, la palabra-lema se suprime en el caso de las formas complejas cuando está en posición inicial. Con esta compresión del artículo se consigue ahorrar espacio a costa de una mayor dificultad de lectura.

En segundo lugar, se establece también una economía de caracteres a través de las abreviaturas, pues se prescinde de las referidas a las categorías gramaticales ( $s$. de sustantivo y $v$. de verbo), ya implícitas en otras abreviaturas que indican el género de los sustantivos $(m$. y $f$., masculino y femenino) o el tipo de verbo ( $a$., $n$. y $r$. para verbo activo, neutro y recíproco, respectivamente). Esta práctica, que se prolonga hasta la lexicografía actual, añade mayor complejidad al proceso de descodificación de la información que exige cualquier diccionario.

En tercer lugar, se encuentra la sustitución de la expresión En algunas partes, que aportaba una restricción diatópica muy imprecisa, por la abreviatura prov. (provincial), utilizada desde la segunda edición del Diccionario de autoridades (Pascual Fernández 2013; Varela 2018).

10 Así, por ejemplo, en la cuarta edición se añadieron señaladamientre, urinar o trespaso que fueron ya suprimidas en la edición siguiente; por su parte, malamentre, lleneramientre, vibdo o arrehen se añadieron en la cuarta edición y se eliminaron en la sexta.

11 Esta disposición del artículo ya se había aplicado en el DRAE 1791, edición en la que se introdujo numeración de las distintas acepciones. La numeración no aparecerá hasta el DRAE 1914. 
En cuarto lugar, se reconoce en el prólogo que se han acortado las definiciones en "términos precisos sin dañar la claridad". En este aspecto, se mencionan específicamente las "voces tomadas de artes y ciencias, y en particular de los diversos ramos que comprenden las ciencias naturales", área en la que se reconoce que se ha intentado reducir los artículos a la par que se procura conferirles mayor "exactitud" con una pequeña reflexión teórica sobre el tipo de definición, más o menos científica, que debe proporcionar un diccionario general (Clavería 2016: 95-99).

Las calas comparativas realizadas para identificar los cambios en la definición introducidos en esta edición indican que se intervino preferentemente, aunque con mucha heterogeneidad, en las entradas pertenecientes a la esfera de las ciencias naturales y, además, se percibe una propensión a acortar ciertas entradas, más que con la revisión general de la definición, con la supresión de la parte final de esta en la que frecuentemente se mencionan los usos, aplicaciones y otras informaciones marginales del concepto descrito (Carriet 2017: 55). Los ejemplos siguientes (cuadro 4) ilustran este tipo de intervención:

\begin{tabular}{|c|c|}
\hline DRAE 1822 & DRAE 1832 \\
\hline $\begin{array}{l}\text { GUAYABO. s. m. Arbol de las Indias, cuyas } \\
\text { hojas son rayadas y algo obtusas, los tallos } \\
\text { cuadrangulares; la flor á manera de rosa } \\
\text { compuesta de muchas hojuelas; el fruto aovado } \\
\text { del tamaño de una pera mediana, blanco, dulce, } \\
\text { con la carne llena de algunos granillos ó semillas } \\
\text { pequeñas. Hay otras especies que producen el } \\
\text { fruto de varios colores, y más ó menos dulces. } \\
\text { Guayaba seu psidium pyriferum. }\end{array}$ & $\begin{array}{l}\text { GUAYABO. m. Árbol de las Indias, cuyas } \\
\text { hojas son rayadas y algo obtusas, los tallos } \\
\text { cuadrangulares, la flor á manera de rosa } \\
\text { compuesta de muchas hojuelas, el fruto aovado } \\
\text { del tamaño de una pera mediana, de varios } \\
\text { colores y mas ó menos dulce, con la carne } \\
\text { llena de algunos granillos ó semillas pequeñas. } \\
\text { Guayaba seu psidium pyriferum. }\end{array}$ \\
\hline $\begin{array}{l}\text { LACRE. s. m. Pasta hecha de laca y otros } \\
\text { combustibles reducida á barritas cilíndricas, } \\
\text { que con el fuego se ablanda, y encendidas y } \\
\text { derretidas sus gotas, se enfrían y adquieren } \\
\text { mucha dureza y lustre, por lo cual sirve para } \\
\text { cerrar cartas é imprimir sellos. Le hay de varios } \\
\text { colores; y el encarnado, que es el mas usado, } \\
\text { proviene de la mezcla del bermellon tan } \\
\text { abundante en España, por lo cual adquirió } \\
\text { fuera de ella el nombre de cera de España. } \\
\text { Cera obsignatoria. }\end{array}$ & $\begin{array}{l}\text { LACRE. m. Pasta hecha de laca y otros } \\
\text { combustibles reducida á barritas cilíndricas, } \\
\text { que con el fuego se ablanda, y encendidas y } \\
\text { derretidas sus gotas, se enfrían y adquieren } \\
\text { mucha dureza y lustre, por lo cual sirve } \\
\text { para cerrar cartas é imprimir sellos. Cera } \\
\text { obsignatoria. }\end{array}$ \\
\hline $\begin{array}{l}\text { MANGOSTA. s. f. Cuadrúpedo de pie y medio } \\
\text { de largo, cubierto de pelo áspero, largo y de color } \\
\text { ceniciento oscuro. Tiene la cola tan larga como el } \\
\text { cuerpo, y adelgazada desde su nacimiento hasta } \\
\text { la punta. Se alimenta de cuadrúpedos y reptiles; } \\
\text { se domestica con facilidad; y en la India, de } \\
\text { donde es indígena, lo crian en las casas como } \\
\text { aca á los gatos. Viverra ichreumon. }\end{array}$ & $\begin{array}{l}\text { MANGOSTA. f. Cuadrúpedo de pie y medio de } \\
\text { largo, cubierto de pelo áspero, largo y de color } \\
\text { ceniciento oscuro. Tiene la cola tan larga como el } \\
\text { cuerpo, y adelgazada desde su nacimiento hasta } \\
\text { la punta. Se alimenta de cuadrúpedos y reptiles. } \\
\text { Viverra ichreumon. }\end{array}$ \\
\hline
\end{tabular}

Cuadro 4 . 
La heterogeneidad que caracteriza esta enmienda se percibe en dos aspectos: en primer lugar, parece más frecuente la intervención en ciertas letras e inexistente o menos frecuente en otras ${ }^{12}$; en segundo lugar, no afecta a todas las voces que tienen unas mismas características - por ejemplo, se da en guayabo, pero no en guayaco- Como ya se ha señalado en otro lugar (Clavería y Paz 2018), esta intervención, por no ser sistemática, genera gran diversidad en la definición de las voces pertenecientes a las ciencias naturales. Cabe recordar que en esta tarea tuvo una importante participación J. Musso y Valiente y se realizó siguiendo las directrices presentadas por el académico citado (Clavería 2016: 95-109).

Por lo que respecta a la supresión de artículos, se menciona en el prólogo que se continúa con el cambio de ubicación de "los verbos usados como recíprocos", cuya modificación se había iniciado en la cuarta edición (Terrón 2017); también se indica en el prólogo que se prosigue con la eliminación de las "voces anticuadas" y las de "viciosa pronunciación", como había ocurrido en la sexta edición. Se añaden, además, en la séptima edición los que se consideran "artículos inútiles", que cargaban el diccionario de materiales lexicográficos de poco valor informativo, mencionándose específicamente los participios pasivos regulares y "los adverbios en mente que proceden de superlativos"; por último, se hace referencia en el prólogo a voces derivadas ("pudiéndose fácilmente formar") y se da como ejemplo de ello los "muchos nombres de accion terminados en azo".

El grueso de supresiones del DRAE 1832 se encuentra, pues, en la intersección entre la gramática y el diccionario: se suprimen más de 5000 participios pasivos, lo cual representa un $80 \%$ del total de las supresiones (Jiménez Ríos 2019: epígrafe 6); también se elimina el artículo destinado al verbo "recíproco" en unos 230 casos, de modo que la entrada abalanzarse desaparece y se genera una nueva acepción para el verbo recíproco en abalanzar (cfr. Terrón 2017); hay, además, entre los lemas de los que se prescinde, formas marcadas como anticuadas (abajeza, abés, calonia, destorbo, medecina, etc.), casi trescientos adverbios en -mente formados sobre bases superlativas (abundantísimamente, altísimamente, doctísimamente, etc.), casi una treintena de formas diminutivas (copilla, lechuguita, etc. ${ }^{13} \mathrm{y}$, como recoge el prólogo, una veintena de derivados en -azo (abanicazo, escobazo, tejazo, etc.).

\subsubsection{El nuevo modelo de diccionario y la periodización de la lexicografía académica}

Las tres ediciones estudiadas comportan una notable y creciente reducción de la nomenclatura del diccionario conseguida con la eliminación de cierto tipo de entradas. Se trata de un tipo de enmienda que está muy relacionada con el proyecto de diccionario manual en el que se trabajó en aquellos años y con las reflexiones metodológicas que este comportó. La posibilidad de elaboración de este nuevo diccionario fue planteada por primera vez por M. de Valbuena en 1814; más adelante, a finales de 1816, se dirimió detenidamente sobre sus características que quedaron plasmadas en el "Plan del diccionario manual", el cual tuvo como base la propuesta realizada por el latinista mencionado. En 1828, volvió a considerarse esta proposición, pero se volvió a descartar. El proyecto tomaba como punto de partida el diccionario usual y proponía la eliminación de ciertos tipos de lemas, por lo que se encuentra en el origen de los cambios que se observan en las ediciones examinadas (DRAE 1817-1832) ${ }^{14}$.

12 Cfr. Carriet (2017: 54) quien señala que este tipo de intervención se incrementa a partir de la letra $F$.

13 En el DRAE 1822 se suprimen también unas 20 formas diminutivas (Terrón y Torruella 2019a).

14 Véase un análisis detallado de esta cuestión en Clavería (en prensa 1). Véanse, además, Cotarelo y Mori (1928: 
Todo ello se trasluce en el tratamiento de los arcaísmos, en especial en la sexta edición (Jiménez Ríos 2018a, Jiménez Ríos 2019), y en las supresiones de participios de la séptima edición. Se acrecienta, de este modo, el alejamiento del diccionario usual con respecto al Diccionario de autoridades.

La reducción se traduce en el decrecimiento físico del diccionario, bien visible en el número de páginas. Si la cuarta edición el diccionario ${ }^{15}$ ocupaba 927 páginas, en la quinta (DRAE 1817) la mengua es mínima (918 páginas); por el contrario, la sexta (DRAE 1822) ya contiene casi cincuenta páginas menos (869 páginas); y, por último, la séptima (DRAE 1832) consigue un ahorro de ochenta páginas (788 páginas).

Los estudios realizados en torno a las tres ediciones consideradas permiten agruparlas formando un subperíodo dentro de la lexicografía académica por compartir ciertas características: la supresión de determinado tipo artículos, la enmienda de las voces pertenecientes a las ciencias naturales, la corrección de las remisiones y de las correspondencias latinas. La quinta edición se configura como la transición entre la metodología de las primeras ediciones del diccionario usual, totalmente dependiente del Diccionario de autoridades, y una nueva lexicografía con una nueva concepción del diccionario. Esto último se consagra en las dos ediciones siguientes con el tratamiento otorgado a las variantes antiguas y el intento de conseguir un diccionario "mas manejable". Las tres ediciones tienen como telón de fondo la existencia de un proyecto de diccionario manual que, aunque no prosperó, dejó una huella indeleble en ellas.

\section{LA LEXICOGRAFÍA ACADÉMICA ENTRE 1837 Y 1852}

En los veinte años siguientes se publican tres ediciones más de este diccionario académico que había sido despojado, entre 1817 y 1832, de parte de un material lexicográfico que se había juzgado prescindible. Coincide esta nueva etapa con la eclosión de la lexicografía no académica de mediados de siglo XIX (Seco 1987; Anglada y Bargalló 1992; Bueno 1995; Esparza 1999; Azorín 2000 y 2007b; García Platero 2003; Álvarez de Miranda 2007; Quilis Merín 2016) en la que destaca el magnífico diccionario de Salvá, que toma como punto de partida el diccionario académico de 1843 (Álvarez de Miranda 2003; Azorín y Baquero 1994-1995; Azorín 2003, 2007a, 2012, 2018b).

La octava edición (DRAE 1837) se publica solo cinco años después de la precedente y entraña una enmienda reducidísima. Las dos ediciones siguientes inician una pequeña ampliación del aumento, que supera las cifras de tres ediciones anteriores pero se queda por debajo de la quinta edición (cfr. gráficos 1 y 2). Suele estar en consonancia el mayor o menor aumento de la nomenclatura con la mayor o menor profundidad de las enmiendas introducidas en la microestructura. A diferencia de las tres ediciones precedentes, los DRAE 1837-1852 presentan unas cifras de supresiones que siempre son inferiores a las adiciones y suelen responder a la prolongación de los criterios aplicados en las ediciones anteriores. Así, se eliminan algunos adverbios acabados en -mente, superlativos, participios pasivos, derivados apreciativos ${ }^{16} \mathrm{y}$ variantes formales (antiguas). Siguiendo las tendencias de la lexicografía académica previa, hay

30), Seco (1994: 540) y Clavería (2016: 77-78, 98).

15 Tengo solo en cuenta el cuerpo del diccionario, al margen de los paratextos y la página o páginas de erratas.

16 Algunas formas sustraídas podrían ser errores de impresión por cuanto corresponden a distintas terminaciones de los lemas múltiples. 
algún caso aislado de unificación de los artículos verbales: por ejemplo, herrumbrarse pasa a herrumbrar en el DRAE 1837. También van desapareciendo las estructuras complejas que se incorporan a una de las palabras de la locución siguiendo los dictados de la quinta edición, de este modo manzanita de dama se incluye en el lema manzanilla/ta en el DRAE $1837^{17}$, y la locución ceca en meca (andar de) se integra en el lema ceca en la décima edición.

\subsection{EI DRAE 1837}

Entre 1832, la fecha de publicación de la séptima edición, y 1837, cuando ve la luz pública la edición siguiente, se han producido importantes cambios en la política nacional. La muerte de Fernando VII, en 1833, la sucesión de su hija, la reina Isabel, y la regencia de su viuda, la reina María Cristina, desataron la primera guerra carlista, que se prolongó hasta 1840. Grandes cambios políticos se produjeron entre 1834 y 1840.

Un año después de la publicación de la séptima edición constató la Academia que quedaba solo la mitad de los ejemplares de la edición para la venta (Actas, 21 de febrero de 1833) e inmediatamente se iniciaron los preparativos para la nueva versión de la obra que se llevaron a cabo entre 1833 y principios de 1837 . Aunque en aquellos momentos se volvió a plantear la posibilidad de publicar un diccionario manual, se optó por la solución menos costosa y más rápida, es decir, la enmienda de la séptima edición por el método habitual de repaso del diccionario anterior (Clavería 2016: 109-110). En el momento de publicación de la octava edición, hacía ya diez meses que se habían agotado los ejemplares de la edición precedente (DRAE 1837: prólogo) por lo que, como en otras ocasiones, la enmienda fue llevada a cabo con el apremio de finalizar las labores de revisión cuanto antes.

En el prólogo se reconoce que la nueva edición sigue las directrices de la anterior. Es un texto breve y en él se incide muy especialmente en las novedades en materia ortográfica del DRAE 1837. En los prólogos de las ediciones anteriores (DRAE 1817-1832), se daba cuenta de las normas seguidas en la ordenación de las formas complejas y en el DRAE 1832 se detallaban los cambios introducidos en las abreviaturas de carácter gramatical. Con buen criterio, en la octava edición se eliminan estas cuestiones del prólogo y se remite para su consulta a la lista de abreviaturas y a las indicaciones que siguen a estas sobre la ubicación de las locuciones (cfr. Alvar Ezquerra 2002 [1993]: 284). También se suprime el párrafo final del prólogo que servía para introducir la lista de académicos que habían fallecido en el ínterin entre dos ediciones (DRAE 1817-1832) $)^{18}$.

El hecho de que casi la mitad de las adiciones de formas y lemas se encuentre en el suplemento significa muy probablemente que se trabajó de forma muy apresurada y desordenada. La imprenta ya había impreso aquella parte del diccionario en la que se quería introducir una adición o una enmienda por lo que hubo que incluir la mayoría de ellas en la parte final del diccionario. Las actas de las sesiones académicas corroboran esta circunstancia cuando repetidamente se menciona que "falta original para la imprenta" y entonces se mandaba a la imprenta el cuaderno que se estaba corrigiendo en aquellos momentos sin concluirlo y se empezaba otro (cfr. Actas, 1836).

17 En algunos casos se podría tratar de una errata en el tipo de letra así juzgado y sentenciado (estar á) figura como lema independiente en el DRAE 1832 y en la edición siguiente se integra en juzgado.

18 Figuraba también como lista separada del prólogo en las ediciones anteriores a la quinta (cfr. San Vicente y Lombardini 2012a). 
Puede hallarse una valoración del aumento de la octava en el trabajo de Julià (2019). Destaca en él, al margen de las voces "fácilmente formables", la presencia de un pequeño grupo de voces de origen griego (arqueología, arqueólogo, demócrata, geognosia), pese a que el prólogo de la edición se encarga de explicar con cierto detalle que la ausencia de voces de este origen en el diccionario responde al hecho de que "tales nombres pertenecen ménos al caudal de los idiomas vulgares, que al lenguaje técnico y peculiar de las ciencias á que se refieren" por lo que, siguiendo los principios académicos ${ }^{19}$, se posterga su admisión hasta que sean de "uso comun". También cabe reparar en algún que otro préstamo con final consonántico extraño a las características fonológicas del español (club, fagot, frac, bambuc-bambú, cfr. Clavería 2018c: 1436). Se descubren, además, varios términos y acepciones relacionados con América que podrían ser debidos a un colaborador externo pues en las actas de las juntas (15 de octubre de 1835) se menciona el examen de "varias observaciones sobre el diccionario remitidas por un americano" (Clavería, en prensa 2; Julià 2019).

Respecto a otros tipos de transformaciones introducidas en la octava edición, pueden observarse ciertos cambios ortográficos, mencionados en el prólogo, como las sustituciones de $g$ por $j$ (por ejemplo, gerarca $>$ jerarca, geringa $>$ jeringa). Se producen, asimismo, modificaciones mínimas en las definiciones, incluida la puntuación, y se solventa algún error de la edición anterior. El terreno en el que se perciben mayores intervenciones se halla en las correspondencias latinas con pequeñas modificaciones aquí y allá, y algunas adiciones de este tipo de información.

\subsection{El DRAE 1843}

Ve la luz pública la novena edición solo seis años después de la precedente en un año especialmente convulso en el que concluye la regencia del general Espartero (1840-1843) y, en diez meses, se suceden tres gobiernos distintos (J. M. ${ }^{a}$ López, S. de Olózaga y L. González Bravo) hasta el inicio del gobierno moderado de Narváez en 1844 y la mayoría de edad de la reina Isabel con solo trece años (Bahamonde y Martínez 1994: 248 y ss.). Sin ninguna duda, destaca el DRAE 1843 por su "magnífico prólogo" (Alvar 2002 [1993]: 260), dos páginas en las que se encuentra una detallada exposición de los principios que regían la ampliación léxica del diccionario académico.

Durante la revisión, se constatan enormes apuros económicos para la publicación de la obra. De toda la serie de diccionarios analizados, es el único que no fue editado por la Imprenta Nacional: las actas de las juntas reflejan las gestiones realizadas por el secretario de la corporación, Juan Nicasio Gallego, para la provisión del papel de la nueva edición del diccionario y, en ellas, se deja constancia de "las dificultades que había por la escasez que se esperimenta por la mala calidad de lo que se halla en los almacenes y por los precios subidos a que se vende" (Actas, 18 de marzo de 1841). Unos meses más tarde, el pleno elige la imprenta de José Alegría y Francisco M. ${ }^{a}$ Fernández en detrimento de la Imprenta Nacional por "ser más ventajosa para la nueva edición del diccionario" (Actas, 25 de noviembre de 1841) ${ }^{20}$.

19 Podría tener origen esta aclaración en la lista de aumento que se recibió de parte de "Francisco Isla de Cádiz" (Actas, 31 de diciembre de 1835), una suposición que baso en el hecho de que en las actas consta la palabra gimnosofista como perteneciente a esta lista; es posible que la existencia de helenismos en ella provocara el comentario que consta en el prólogo de esta edición.

20 Consta en el acta el precio de cuatrocientos reales por pliego. 
En el proceso de impresión, surgen graves contratiempos tanto con la imprenta como con la provisión de papel (Actas, 7 de abril de 1842) (1) $^{2}$, estas dificultades se debieron afrontar con la petición de un préstamo por valor de ochenta mil reales para sufragar la compra de papel, una suma que la Academia se comprometía a pagar en el plazo de dos años e hipotecando "sus bienes y efectos, y especialmente las existencias de sus impresiones" (Actas, 21 de julio de 1842; cfr. Matilla 1982). Los trabajos de impresión, por su parte, no fueron de calidad pues se ha podido identificar un elevado número de erratas en los lemas (cfr. Lemateca del $D R A E$ ), incluso algunas de las supresiones verificadas en esta edición podrían deberse, en realidad, a un descuido o error de impresión porque son recuperadas en la edición siguiente ${ }^{22}$. A todos estos contratiempos hay que sumar que la etapa final de la enmienda coincidió con las sombras del prospecto del Panléxico de J. Peñalver, publicado por el impresor I. Boix. La Academia se sintió muy agraviada por las críticas hacia su diccionario que contenía este texto (Seco 1987: 131-134; Clavería 2016: 113, 121-122; Puche 2019: epígrafe 5.2).

Puede hallarse una información detallada del aumento de lemas de la novena edición en los trabajos de Freixas (2019) y Muñoz (2019). Por lo que respecta al resto de enmiendas introducidas en esta edición, se percibe la inclusión de acepciones nuevas en algunas entradas (por ejemplo, astrágalo, baboso, catastro, guapo, vocero); son muy abundantes los cambios leves en la redacción de las definiciones añadiendo y suprimiendo alguna palabra (e. g. meritorio, tostado) y, más raramente, se produce una reescritura de la definición de mayor calado (por ejemplo, tos). Como en los lemas, no es difícil encontrar erratas de impresión en la microestructura del diccionario, unas erratas que no pasaron desapercibidas en las valoraciones críticas de los medios periodísticos de la época (Puche 2019: epígrafe 6).

\subsection{EI DRAE 1852}

Casi diez años transcurrieron entre la novena y la décima edición del diccionario y, con esta última, se inicia ya la segunda mitad del siglo XIX. Muchos son los cambios que se producen durante esta década tanto en el seno de la Academia, como en la historia de la lexicografía no académica, amén de los sucesos históricos y políticos de este período, presididos por la década moderada (1844-1854) en la que se desarrolló una amplia labor legislativa. Se produce en los años cuarenta un reforzamiento oficial de la corporación con una revitalización de sus labores. Todo ello afecta tanto a su funcionamiento y organización como a su función cultural y social: si al año siguiente de la publicación de la novena edición del diccionario se decreta la oficialidad de la ortografía de la Academia, en 1847 se reorganiza, también por decreto oficial, la composición de la Academia con una ampliación significativa del número de sus miembros, se elaboran unos nuevos estatutos y se instaura la ceremonia de recepción de los nuevos académicos y la impresión de los discursos pronunciados en los actos de recepción (Ferrer del Río 1870 [1860]; Roca de Togores 1870; Fries 1973: 65-67; Zamora 1999: 37-40; Álvarez de Miranda 2011; García de la Concha 2014: 189-205). Paralelamente, se produce la eclosión de la lexicografía no académica con

21 Y más tarde con la encuadernación porque parece que faltaban algunos pliegos (Actas, 14 de septiembre de 1843).

22 Por ejemplo, patriarcado (probable error de eliminación por patriarcadgo), penuria, rapto, repúblico, subtender, tiritona, trafagar, vaguear son recuperadas en el DRAE 1852. 
lo que la labor lexicográfica de la corporación se constituye en el punto de partida de estos diccionarios a la vez que en el blanco de todas las críticas (Jiménez Ríos 2013). La novena edición del diccionario es sometida a un análisis y revisión microscópicos y rigurosísimos de la mano de V. Salvá (Álvarez de Miranda 2003; Azorín 2003).

La nueva edición se publica en este ambiente de cambios, pero surge aún de una revisión en la que se siguen los patrones aplicados hasta aquellos momentos. Se refleja en las transformaciones que alberga una mayor ampliación que en la edición anterior (cuadros 1 y 2), cuyo análisis puede encontrarse en el trabajo de Buenafuentes (2019). El prólogo de esta edición es muy breve y sustituye el título habitual (prólogo) por "Al lector", un encabezamiento que se mantiene también en la edición siguiente (cfr. San Vicente y Lombardini 2012a: 74-75). Atrás queda el prólogo programático de la novena edición, aunque se tome como referente de la décima edición. Las palabras de presentación de esta última contienen una idea novedosa dentro del ideario lexicológico académico: se reconoce que una forma de enriquecimiento léxico que entraña el diccionario se encuentra en la eliminación de "la inmerecida nota de anticuadas cuando por plumas doctas las ha visto rejuvenecidas", algo que anuncia la nueva consideración del arcaísmo que se desarrollará en los años siguientes y de la que serán un claro exponente tanto la existencia de un proyecto de diccionario de arcaísmos como el discurso de P. F. Monlau pronunciado en 1863 (Clavería 2016: 140-144, 162-168). Pese a ello, se continúa, en la línea de las reformas realizadas en la sexta edición, desechando "las que caducaron no mucho después de haber adquirido forma propia, regularidad y robustez nuestro romance".

En la microestructura del diccionario, se percibe una mayor enmienda que en las ediciones anteriores, no solo en la ampliación de acepciones y de formas complejas (general [3], informar [2], informe [2], etc.), sino también con ciertas reducciones anunciadas en el prólogo: "se han suprimido algunas locuciones por impropias ó por conocidamente supérfluas", una intervención que puede ilustrarse con los cambios registrados en la entrada refregón (cuadro 5):

\begin{tabular}{|c|c|}
\hline$D R A E 1843$ & $D R A E 1852$ \\
\hline $\begin{array}{l}\text { REFREGON. m. El estregon ó ludimiento de una cosa } \\
\text { con otra. Collissio. } \bullet \text { Aquella señal que queda de haber } \\
\text { ludido alguna cosa. Macula ex collisione. } \bullet \text { met. y fam. } \\
\text { El gusto ó disgusto breve y de paso que se tiene con } \\
\text { otro. Collusio, colloquium. } \bullet \text { DARSE UN REFREGón. fr. } \\
\text { met. y fam. Hablar ligeramente sobre algun asunto ó } \\
\text { materia. Perfunctoriè colloqui. }\end{array}$ & $\begin{array}{l}\text { REFREGON. m. El estregon ó } \\
\text { ludimiento de una cosa con otra. } \\
\text { Collissio. \| Aquella señal que queda } \\
\text { de haber ludido alguna cosa. Macula ex } \\
\text { collissione. }\end{array}$ \\
\hline
\end{tabular}

\section{Cuadro 5.}

No sorprende encontrar abundantes cambios en el uso de la abreviatura ant: se identifican lemas y acepciones en los que se añade (aceituní, acender, cruentidad, dehecha 4, infirmar, etc.); casos, más numerosos, en los que se suprime la notación de anticuado (asentador, geneático, hastiar, infesto, infligir, infortunadamente, infortunado, suscitación, etc.); y lemas y acepciones en los que se produce algún tipo de sustitución en la 
abreviatura — por ejemplo, en caudal [6] se sustituye ant. por Poét.—. Estas actuaciones prueban la enmienda llevada a cabo en este tipo de información.

El prólogo advierte que se introducen distintas enmiendas en las definiciones y, efectivamente, se detecta un amplio abanico de transformaciones en este terreno (cuadro 6): desde modificaciones de detalle (toledano) hasta cambios de mayor calado (suscribir), que pueden mejorar la estructura de los artículos (toga), aunque también pueden introducir errores derivados de las propias enmiendas (la correspondencia latina de toga). Se han identificado, además, abundantes cambios en las localizaciones americanas a tenor de los cambios políticos producidos con la independencia de las colonias (tostón y perulero, cfr. Clavería, en prensa 2)

\begin{tabular}{|l|l|}
\hline \multicolumn{1}{|c|}{ DRAE 1843} & \multicolumn{1}{|c|}{ DRAE 1852} \\
\hline $\begin{array}{l}\text { TOLEDANO, NA. adj. El natural de Toledo y lo } \\
\text { perteneciente á esta ciudad. Toletanus. }\end{array}$ & $\begin{array}{l}\text { TOLEDANO, NA. adj. El natural de Toledo y } \\
\text { lo perteneciente á esta ciudad y su provincia. } \\
\text { Toletanus. }\end{array}$ \\
\hline $\begin{array}{l}\text { SUSCRIBIR. r. Obligarse á contribuir con una } \\
\text { cantidad determinada ó anticipar su para para } \\
\text { tener derecho á las ganancias de alguna empresa, } \\
\text { ó recoger á menos precio una obra literaria } \\
\text { para que se hace la suscripción. Pignore soluto } \\
\text { subscribere. }\end{array}$ & $\begin{array}{l}\text { SUSCRIBIR. r. Obligarse á contribuir en } \\
\text { compañía de otros al pago de alguna cantidad } \\
\text { para cualquiera obra o empresa comun. Pignore } \\
\text { soluto subscribire. }\end{array}$ \\
\hline $\begin{array}{l}\text { TOGA. f. Vestidura talar con mangas que } \\
\text { usaban los romanos. Ahora solamente la traen } \\
\text { los ministros letrados de las audiencias. Toga. } \\
\text { La misma dignidad de magistrado ó ministro. } \\
\text { Senatoria dignitas. }\end{array}$ & $\begin{array}{l}\text { TOGA. Vestidura talar que usaban los romanos. } \\
\text { I Las que usan los magistrados y los abogados } \\
\text { en traje de ceremonia. Senatoria dignitas. }\end{array}$ \\
\hline $\begin{array}{l}\text { TosTon [6] prov. En Nueva España y en el } \\
\text { nuevo reino de Granada el real de á cuatro. }\end{array}$ & $\begin{array}{l}\text { Toston [6]. En Méjico y en Granada de Amé- } \\
\text { rica el real de á cuatro. }\end{array}$ \\
\hline $\begin{array}{l}\text { PERULERO, RA. adj. El natural del Perú y } \\
\text { lo perteneciente á este reino. Peruanus, peru- } \\
\text { vianus. El que ha venido desde el reino del Perú } \\
\text { á España. Peruvianus [... }\end{array}$ & $\begin{array}{l}\text { PERULERO, RA. adj. El natural del Perú y lo } \\
\text { perteneciente á este país. Peruanus, peruvianus. } \\
\text { El que ha venido desde el Perú á España. } \\
\text { Peruvianus [... }]\end{array}$ \\
\hline
\end{tabular}

Cuadro 6.

La revisión que conlleva la décima edición intenta perfeccionar el diccionario en otros aspectos: se perciben adiciones de abreviaturas de carácter gramatical cuando faltaban ( $\mathrm{ca}$ tavinos, envoltura, gelatinoso) y adición de notaciones de uso (Blanco y Clavería 2019); asimismo, en las entradas del participio activo se completa la referencia al infinitivo cuando este no constaba en las ediciones anteriores (dominante, examinante, forzante, vacante, etc.). No falta, además, la consabida atención a las correspondencias latinas, limitada casi exclusivamente a cambios y correcciones formales ${ }^{23}$.

23 Muchas de las erratas corregidas habían sido introducidas en la novena edición, y se incluyen ahora nuevos errores como puede observarse en las correspondencias de refregón con homogeneización en doble $s$ de las dos equivalencias (collissio/colissione) en lugar del clásico collisio, onis. 


\section{EL CONCEPTO DE NORMA EN EL DICCIONARIO}

Se percibe en las ediciones estudiadas la conformación progresiva de la Academia y sus decisiones como norma, tanto desde el punto de vista léxico como desde el punto de vista ortográfico.

\subsection{La norma léxica}

A la par que se gesta un nuevo modelo de diccionario, que surge de las supresiones practicadas en las tres primeras ediciones estudiadas, empieza a perfilarse en el pensamiento lexicográfico académico un nuevo concepto de norma léxica basado en la función del propio diccionario como instrumento normativo. Ello es especialmente visible en el prólogo de la sexta edición y, unos años más tarde y de una forma mucho más clara, en el de la novena edición.

Ya notó Lombardini (2011: 312) que, en el prólogo de la quinta edición, aunque no se

habla explícitamente de norma, pero se introducen expresiones como "promover el conocimiento y perfeccion de nuestro idioma" (§ 1), "admitir en el Diccionario" una voz ( $\S$ 10), "la Academia [...] puede dirigir" el uso (§ 22), "siguiendo y adoptando [...] consejos é insinuaciones" de la Academia ( $\$ 22)$, todas expresiones que, si bien no establecen una norma, apuntan seguramente hacia ella.

Efectivamente, la presentación del DRAE 1817 es sustancialmente distinta de la de la edición anterior (San Vicente y Lombardini 2012b) y, aunque algunas de estas expresiones se refieren al sistema ortográfico adoptado, las palabras preliminares aluden a las directrices que guían la admisión de nuevo léxico mediante la aplicación de "la severidad que aconseja la conservación de la pureza de la lengua", siempre sustentada en la autoridad y el uso común, dos principios que tradicionalmente han regido la admisión de las voces en el diccionario (San Vicente 2010; Clavería 2016: 245-248; Azorín 2017).

Como se ha observado anteriormente, en la edición siguiente (DRAE 1822) se optó por introducir supresiones en la nomenclatura claramente orientadas hacia las variantes formales de una voz, ya fueran antiguas, ya fueran variantes ligadas a la "torpe pronunciación de la gente rústica por el vicio contraído y aun casi peculiar de algunas provincias, ó la corrupción de los tiempos del mal gusto y la decadencia de las letras". La aplicación de este principio provocó que desaparecieran del diccionario entradas como abtoridad y abtoridat, marcadas como anticuadas, y también formas que figuraban desprovistas de esta marca como bredo, variante de bledo, o amimar, variante de mimar. Aunque el grueso de las supresiones pertenece al primer grupo, es decir, a las anticuadas, la razón de las supresiones se encuentra en la voluntad de erradicar las variantes formales consideradas no normativas, es decir, las "alteraciones viciosas" (cfr. Lombardini 2011: 312). Pese a que no se reconoce explícitamente, se colige de todo ello que la supresión de este tipo de entradas implica su incorrección.

Los mismos principios se mantienen en la edición siguiente, que se declara seguidora del plan marcado en la anterior y continúa sustrayendo voces anticuadas; y esta vez se añade: "con mas razon ha proseguido suprimiendo los vocablos que solo por viciosa pronunciación se diferencian en algo de los propios y castizos" (DRAE 1832: prólogo). Se hace referencia, 
además, en el texto de presentación al proceso seguido en la admisión de voces nuevas saliendo, de este modo, al paso de las críticas al diccionario académico, críticas que no pueden comprenderse sin apelar a la lexicografía no académica. Efectivamente, en el siglo XIX, la eclosión de los diccionarios monolingües generales "no académicos" cambia completamente el panorama de la lexicografía española. Estos diccionarios se constituyen en un producto editorial cuyo objetivo era, justamente, "romper el monopolio efectivo de que disfrutaba la Academia en el terreno de la lexicografía del español” (Seco 1987: 130). Su existencia no puede entenderse fuera de la situación política de la España de la primera mitad de siglo XIX, pues son obras que están ligadas a editores franceses cuando "estos descubrieron las posibilidades que les brindaba el mercado de las recién emancipadas colonias españolas de América -roto el comercio de ellas con España" (Seco 1987: 130). Sus autores eran, a menudo, exiliados que se dedicaron a tareas de traducción y elaboración de materiales para la enseñanza de la lengua. Buen ejemplo de ello es Manuel Núñez de Taboada, un afrancesado gallego que residió en Francia desde 1808. Fue autor de diccionarios bilingües y también de un diccionario monolingüe general (Núñez de Taboada 1812, 1823 y 1825), a los que la Academia prestó atención espoleada por las críticas al diccionario académico que su autor incluyó en los prólogos de sus obras. Así y como se ha demostrado con anterioridad (Clavería 2007 y 2016: 95-105), el prólogo de la séptima edición contiene algunas referencias indirectas a la obra de Núñez de Taboada cuando expone detalladamente los motivos de la exclusión de ciertas palabras del diccionario académico:

como no falta quien todavía acuse de escasez al Diccionario académico, echando menos en él voces que en su concepto debieran incluirse, la Academia tiene por conveniente advertir que ahora y siempre ha procedido con suma circunspeccion en dar lugar á voces que no le han tenido anteriormente; porque el verdadero caudal de las lenguas vivas no se compone sino de las palabras y frases usadas generalmente entre las personas cultas. La Academia ha sido severa en esta calificacion; y lejos de adoptar fácilmente y sin mucho examen voces y locuciones nuevas, ha desechado todas las que no se hallan autorizadas por el ejemplo de nuestros escritores clásicos ó por el uso claramente reconocido como general y constante. Muchas veces ha diferido la admision, dando tiempo á que se prescriban voces bien formadas, que empiezan á introducirse, y suenan ya con alguna aceptacion entre las demás del lenguaje. Así que ha excluido nombres caprichosos y pasageros de trajes y modas que hoy se emplean y mañana desaparecen para no volverse á oir nunca. Por igual razon ha excluido infinitas voces técnicas de ciencias, artes y oficios que no pertenecen al lenguaje comun, único objeto del Diccionario. Por la misma no ha admitido las voces fácilmente formables, propias del estilo familiar que permite el uso momentáneo de una voz, pero sin darle derecho al uso perpetuo, de lo que hay ejemplos en nuestros buenos escritores. Si se diera entrada á estas y otras clases de voces en el Diccionario, fácil cosa fuera añadirle no solo cinco sino muchos mas millares de artículos. Sirva esto para satisfacer la delicadeza de los que todavía pudieran tachar al Diccionario de escaso y diminuto. Y prescinde la Academia de los reparos que se han opuesto al suyo por no hallarse en él algunos artículos de voces extrangeras como mutualmente; ó de voces estropeadas y desfiguradas como Barberescos; ó escritas con mala ortografía como uraño; ó pronunciadas á la manera del ínfimo vulgo como hespital ${ }^{24}$. Adoptar artículos de esta especie sería no enriquecer sino manchar el Diccionario, y profanar el carácter del noble y magestuoso idioma de Castilla (DRAE 1832: prólogo).

24 Todos los ejemplos citados se encuentran en la nomenclatura del diccionario de Núñez de Taboada. 
El valor normativo del diccionario en materia léxica hace su aparición de forma muy clara en el prólogo de la novena edición (Lombardini 2011: 312-313). En este se defiende el trabajo colectivo y su valor frente al trabajo individual, una de las diferencias fundamentales entre la lexicografía académica y la no académica (Esparza 1999; Lliteras y Hernández 2008: 244). En este carácter colectivo se sustenta el que el diccionario pueda

servir de norma á los que deseen hablar y escribir su idioma con propiedad y pureza, adquirir fuerza legal é indeclinable en los asuntos contenciosos, en que la genuina inteligencia de una voz suele ser de gran peso en la balanza de la justicia; y por último, solo así podrá llenar cumplidamente su objeto, igual en todo al que de un contraste autorizado para calificar la verdadera ley y valor de los metales preciosos (DRAE 1843: prólogo ${ }^{25}$.

Aparte de la aparición del término norma, en el prólogo de la novena edición se clarifica qué significa que una palabra no forme parte del diccionario: "cuando no encuentran en el Diccionario una voz que les es desconocida, en vez de inferir que no es legítima y de buena ley, lo que infieren es que el Diccionario está diminuto"; para mayor abundamiento, se ejemplifica la cuestión recurriendo a las voces comité y secundar para las que se proponen las equivalencias de comisión y cooperar, respectivamente, y se discurre detenidamente sobre los límites de la presencia de la nomenclatura científica en el diccionario. En palabras de Seco (1987: 138), se opta por la defensa de un modelo de diccionario "en su forma más pura o restrictiva, el léxico general 'correcto' y sin tecnicismos”.

La exposición detallada de las fronteras del diccionario y de los principios de la admisión léxica pudieron ser una reacción a las críticas recibidas en aquellos años (Clavería 2016: 121-122), ante las que la Academia reaccionó reforzando la postura "severa" en la admisión de las novedades, siempre respaldada "por el uso de los buenos escritores", recogiendo las palabras propias del "lenguaje comun", en el que se establece la distinción diastrática entre el uso "familiar", el "culto" y el "poético". No sorprende, pues, que en el aumento de la novena edición figure la admisión de una palabra como neologismo definida con el valor negativo que tenía en aquellos tiempos (Lliteras y Hernández 2008: 232-234; Martínez González 2015; Clavería 2016: 13-34; Clavería 2017) ${ }^{26}$.

Aunque en las primeras líneas del texto preliminar de la décima edición se reconoce que se sigue "el plan" de la anterior, parece percibirse en el prólogo un leve cambio frente a las innovaciones léxicas que quizá anuncia el discurrir de la lexicografía académica de la segunda mitad de siglo. Las sendas de la mejora de la décima edición del diccionario han sido varias: por un lado, se han incluido voces "modernamente introducidas" por haberse generalizado y, en este terreno, se mencionan explícitamente las de "la administracion pública por consecuencia de las actuales instituciones políticas" y las de "las artes, el comercio y la industria" (cfr. Buenafuentes 2019); por otro lado, se revisa el uso de la nota de voz anticuada (ant.) y se elimina en las voces y acepciones que no la merecían por ser usadas por "plumas doctas". Se continúa, sin embargo, mostrando "severidad" en el caso de las "voces novísimas" que no se admiten bien por su grado de tecnicidad, bien por su poco uso, bien por ser muy recientes y posponer su inclusión para más adelante y hacerlo "con mayor autoridad".

25 La negrita es mía.

26 Neologismo se define como "vicio que consiste en introducir voces nuevas en un idioma" (DRAE 1843) y no se utiliza en el prólogo de la novena edición. 


\subsection{La norma ortográfica}

También comparten todas las ediciones una mayor o menor preocupación por la ortografía y la función del diccionario en la fijación ortográfica de cada palabra, unas ideas que aparecen claramente expresadas en algunos prólogos (DRAE 1817, 1832, 1837, 1843). La quinta edición es, sin ninguna duda, el ejemplo más significativo por cuanto en ella se aplica la reforma publicada dos años antes en la Ortografía de 1815 (Clavería 2018a: 20-21; Blanco 2018; Terrón 2018b); se trata de una reforma que es presentada con gran orgullo: "los progresos de nuestra ortografía, que en manos de la Academia ha llegado á ser de las mas sencillas y claras, y por consiguiente de las mas perfectas de Europa" (DRAE 1817: prólogo).

Los prólogos testimonian el cambio registrado en la progresiva creación de la percepción normativa de la propia corporación. En la quinta edición se menciona la existencia de cierta variación en el uso ortográfico y se admite que su fijación no corresponde únicamente a la Academia:

el uso fluctúa, y la Academia que puede dirigirlo, no tiene derecho por sí sola para fijarlo. Es de desear que la práctica comun y general señale y establezca reglas sencillas, uniformes é inalterables en esta materia; y la Academia que ha experimentado ya la docilidad con que la nacion ha contribuido á realizar las mejoras ortográficas de la lengua castellana, siguiendo y adoptando sus consejos é insinuaciones, asi como aprovecha esta ocasión de manifestar su gratitud por tan honrosa deferencia, asi tambien espera que el uso de las personas instruidas y de los buenos impresores continúe auxiliando sus deseos de dar la última mano á la perfeccion de este ramo de nuestra cultura (DRAE 1817).

Esta concepción cambiará con el tiempo y, ya en el prólogo de la octava edición, la Academia expresa su oposición al uso de la grafía es por ex (estraño, extraño) y, de forma mucho más determinante, al uso de $c s$ en lugar de $x$ (ecsamen, examen), práctica que califica de repugnante. Unos años más tarde, en 1844, se publica el Prontuario de Ortografía de la Lengua Castellana, dispuesto de Real Órden para el uso de las escuelas públicas por la Real Academia Española, con arreglo al sistema adoptado en la 9. ${ }^{a}$ edición de su Diccionario, como resultado de la real orden del 25 de abril del mismo año que obligaba a enseñar en las escuelas la ortografía de la Academia, lo que, en palabras de Rosenblat (1951: CXXIV-CXXVIII) “representa la oficialización de la ortografía académica".

\section{CONCLUSIÓN}

Las seis ediciones analizadas en este estudio y en el proyecto cubren un período de tiempo de casi cincuenta años, desde que se inicia la enmienda para la quinta edición del diccionario, en 1803, hasta la publicación de la décima edición a finales de 1852. Entre tres de estas ediciones no transcurren más de cinco o seis años (DRAE 1817-1822, 18321837 y 1837-1843), mayor lapso de tiempo discurre entre las otras tres (DRAE 1803-1817, 1822-1832, 1843-1852). Ciertamente, puede observarse en los prólogos y en las actas de las juntas de esta época la urgencia con la que la Academia preparó cada nueva edición, debido a la falta de ejemplares de la precedente; cabe recordar, a este respecto, las palabras de Alvar (2002 [1993]: 259): "Una pesadilla continua ha sido el agotamiento de las sucesivas ediciones, sin dar respiro para que se pudieran preparar las nuevas con cuidado y premura”. 
Esta permanente premura por dar al público una nueva edición del diccionario impidió la culminación de un diccionario manual, un proyecto que, de una forma $\mathrm{u}$ otra, estuvo muy presente en las labores lexicográficas de la Academia entre 1814 y 1833 . Aunque este modelo de diccionario no prosperó, como se demuestra en Clavería (en prensa 1), varias de las reformas proyectadas en él pasaron al diccionario usual por lo que las supresiones de las tres primeras ediciones estudiadas no pueden contemplarse al margen del diccionario manual. En un ambiente de carencia de medios y de urgencias en la preparación de cada nueva edición del diccionario, resultaba más sencillo revisar más o menos someramente la edición anterior que emprender transformaciones de mayor envergadura.

De hecho, las tres primeras ediciones estudiadas entrañan un proceso de conversión del diccionario hacia un nuevo modelo de obra, un nuevo concepto de diccionario. ¿Cómo se llevó a cabo esta conversión? En primer lugar, con un interés limitado por las incorporaciones; esto se refleja en el descenso progresivo de la adición de entradas desde 1817 hasta 1832 (y, más aún, en 1837). En segundo lugar, la presencia de supresiones de lemas como forma de aligerar el diccionario de unos componentes lexicológicos de los que se podía prescindir por ser o bien variantes textuales ligadas a la transmisión de los textos antiguos y desligadas del uso contemporáneo, o bien variantes no normativas, o bien entradas fácilmente explicables a través de la gramática. La reorientación de la presencia de lo anticuado en el diccionario, en especial en las ediciones de 1817 y 1822 (Jiménez Ríos 2001, 2017a, 2017b, 2018a, 2018b, 2018c, 2018d), es un cambio que, al no ser sistemático, no acaba de ser ni completo ni homogéneo ${ }^{27}$. En tercer lugar, estas tres ediciones exhiben un notable interés por el perfeccionamiento de la definición; sus prólogos se refieren a la intervención en este punto y mencionan de manera específica la realizada en el área de las ciencias naturales ${ }^{28}$.

La atención de estas tres ediciones a cuestiones metalexicográficas se refleja en varias transformaciones: por ejemplo, la simplificación de la diversidad de abreviaturas de carácter diacrónico y estilístico de la quinta edición, que confiere mayor uniformidad a las informaciones del diccionario, aunque menor precisión a la notación; también en la quinta edición se introduce la reorganización en la ubicación de las formas complejas con la aplicación de criterios gramaticales; las mejoras en el sistema de remisiones en la sexta edición (Terrón y Torruella 2019b) y la variación en la disposición del artículo con cambios en el sistema de abreviaturas gramaticales y la eliminación de las entradillas en la séptima edición. Se produce con todo ello una redefinición de los límites de la gramática en el diccionario (Jiménez Ríos 2019: epígrafes 2-4) con una reducción del artículo lexicográfico y, por extensión, del diccionario.

27 Los mismos prólogos de los DRAE 1822 y 1832 anuncian esta asistematicidad. En ambos casos se señalan los límites, muy imprecisos, de la supresión: “Aun en estas reformas se ha procurado suprimir solo aquellas voces cuyo significado se comprende con facilidad, y cuya composicion y carácter se ha conservado en las que se les han sustituido" (DRAE 1822: prólogo) y "conservándose sin embargo algunas para que no se olvide totalmente su uso antiguo, como Atal, Abastar \&c" (DRAE 1832: prólogo). Estas decisiones explican que hayan llegado este tipo de formas hasta las últimas ediciones del diccionario (cfr. Jiménez Ríos 2001: 53-54; Gutiérrez Cuadrado 2001-2002: $312)$.

28 El sentido de la enmienda es distinto al contrastar el prólogo de la quinta edición con el de la séptima, pero la unidad entre estas tres ediciones se corrobora con la existencia del "Plan sobre las reglas que pudieran adoptarse para la redacción de los artículos pertenecientes a Ciencias Naturales en el diccionario manual" elaborado por J. Musso en 1828. Esta necesidad de reforma se manifiesta ya al iniciar las labores para la sexta edición (Clavería 2016: 75 y nota 52). Cfr., además, Clavería, Freixas y Torruella 2019. 
Todas las ediciones estudiadas parecen compartir ciertas características comunes: una parte importante de la ampliación está basada en voces "fácilmente formables". Aunque en los prólogos (DRAE 1817 y 1832) se afirme que el aumento no se hace en este tipo de voces, lo cierto es que en todas ellas constituye una parte nada despreciable. También las voces marcadas con la abreviatura de familiar están más o menos presentes en la ampliación de todas las ediciones u otros grupos léxicos como las designaciones de oficios (Clavería y Freixas 2015, Clavería 2018a, Terrón 2018a, Carriet 2017, Julià 2019, Freixas 2019, Buenfuentes 2019). Prevalece en esta forma de proceder el léxico castizo, mientras que se aplican criterios mucho más "severos" en el léxico foráneo y, muy especialmente, en el léxico facultativo, para el que se mantienen en todo el período unos confines bien claros para su admisión (Clavería y Paz 2018, Garriga 2019, Muñoz 2019).

Contrastan los cambios que tienden hacia la economía con la persistencia en la conservación de las correspondencias o equivalencias latinas, un tipo de información que se remonta al primer Diccionario de autoridades (Freixas 2010: 191-192) y que tuvo una relevancia especial en el quehacer lexicográfico académico; prueba de ello es la existencia de una comisión de equivalencias latinas y de revisores que las supervisaban desde 1749 hasta 1853 (cfr. Roca de Togores 1870: 67-68). Para Alvar Ezquerra (2002 [1993]: 277), la presencia de las equivalencias "era, aún, un resto heredado de la tradición de nuestra lexicografía bilingüe" y no hay que olvidar, además, que algunos diccionarios monolingües latinos incorporaron equivalencias multilingües al final del artículo con lo que no sorprende la presencia de este tipo de información, en este caso del latín, en los diccionarios monolingües de lenguas modernas. Aunque en alguna ocasión se planteara su supresión ${ }^{29}$, no solo se conservan en todo el período estudiado, sino que son objeto de examen, más o menos escrupuloso, con lo que puede comprobarse el conservadurismo de esta etapa, más cuando muchos diccionarios no académicos prescindieron de esta información (cfr. Seco 1987: 150-151). Las supresiones y reducciones de variado tipo introducidas en las tres primeras ediciones estudiadas no afectaron a una parte del artículo lexicográfico que se mantuvo en aras de la enseñanza del español como lengua extranjera y la internacionalidad del diccionario, incluso cuando, en los primeros decenios del siglo XIX, el español se impone definitivamente al latín en todos los frentes (Lázaro 1949 [1985]; Gutiérrez Cuadrado 1987, 1988; San Vicente 1996: 623-626) ${ }^{30}$. Buena muestra de la forma de pensar que subyace al tratamiento de las correspondencias latinas se encuentra en los prólogos de las cuatro primeras ediciones analizadas en los que se resaltan explícitamente las mejoras introducidas en ellas. Cabe reparar en el párrafo que contiene la presentación de la séptima edición dedicado a exponer detalladamente el valor de este tipo de información que se vincula, nada menos, que a "fijar mas bien el significado de las palabras" (DRAE 1832), algo que se contempla como un auxilio en la consulta del diccionario tanto para los extranjeros como para los nativos. De hecho, en los cotejos realizados entre las distintas ediciones ha podido observarse que en las cuatro primeras ediciones

29 Ello ocurre en 1818 (Actas, 19 de mayo de 1818).

30 El proyecto de diccionario manual de la Academia preveía la conservación de las equivalencias latinas con cierta simplificación con lo que puede observarse la importancia que se otorgaba a este tipo de información en la constitución de un diccionario de estas características. Esta decisión contrasta con el proyecto de diccionario manual presentado a la Academia por M. de Valbuena; en este no aparecían equivalencias latinas y así se encuentra en el ejemplar manuscrito del Diccionario manual de la lengua castellana que entregó a la Academia en 1816 (cfr. Archivo de la Real Academia Española, legajo 293). 
estudiadas se introduce un buen número de adiciones y modificaciones. Las dos últimas no mencionan la intervención en las correspondencias latinas en la enmienda y nuestros resultados de análisis indican que la revisión no fue tan importante. Cabe advertir, además, que la novena edición introdujo abundantes erratas en esta parte del artículo y que estas, en algunos casos, fueron subsanadas en la edición siguiente. Esta (DRAE 1852) es la última que contiene las correspondencias latinas, en las ediciones siguientes y ya en un paradigma lexicográfico distinto, se impondrá su supresión.

La relación entre el diccionario y la sociedad se refleja, por ejemplo, en el continuo agotamiento de existencias de ejemplares y en las interesantes noticias periodísticas recabadas por Puche (2019). El interés social que despertaba la obra se trasluce también en la existencia de propuestas de mejora y ampliación de la obra que la Academia recibía de personas ajenas a la corporación. En general, el examen de estas propuestas se realizaba en las juntas con el análisis de cada una de las palabras sugeridas y se elegían las voces que se consideraban dignas de constar en el diccionario por satisfacer los presupuestos académicos de selección léxica. Así, en el transcurso de la enmienda para la sexta edición, se puede identificar el reconocimiento de diversas listas recibidas entre 1818 y 1821 (Clavería 2016: 89-90), lo mismo ocurre en las tres ediciones siguientes (Clavería 2016: 95, 110, 113 y 122-123). Destaca, además, la participación de Gregorio García del Pozo, autor de varias obras de ortografía, ortología y acento (Clavería 2016: 110; Azorín y Martínez 1988-1989), cuya colaboración está asegurada desde 1830 hasta $1842^{31}$, y el material recibido durante la elaboración de la octava edición (epígrafe 5.1). Los mismos prólogos se hacen eco de estas contribuciones con la obligada expresión del agradecimiento académico. Así, en la quinta edición y al presentar el suplemento del diccionario, se hace referencia a las "personas que han querido contribuir con sus noticias y advertencias al aumento del Diccionario" (DRAE 1817); también en el prólogo de la sexta edición se menciona el auxilio de "algunas personas doctas" tanto en el aumento como en la corrección de "algunos descuidos ó negligencias en las definiciones ó en las remisiones á otros artículos" (DRAE 1822), mientras que en la edición siguiente se alude a las "cédulas y notas" de "algunos sabios españoles celosos del buen lenguaje" (DRAE 1832: prólogo). La Academia siempre se muestra agradecida, aunque desde las palabras preliminares del diccionario recuerda que en algunos casos las voces propuestas no se pueden admitir debido al grado de tecnicidad que presentan en su uso (DRAE 1822, 1832 y 1843), pues este se constituye en uno de los caballos de batalla de la admisión de voces en esta época. Cabe preguntarse hasta qué punto pudieron influir estas propuestas en el conjunto de la enmienda del diccionario.

En suma, el devenir del diccionario de la Academia no puede sustraerse del mundo al que pertenece y de las circunstancias que lo envuelven. En una época de no poca inestabilidad y notables cambios políticos y sociales, los procesos de revisión del diccionario fueron parciales $^{32}$ y se realizaron, como no podía ser de otro modo, de manera artesanal y como empresa colectiva con lo que se perciben en ellos dos tendencias contrapuestas: una orien-

31 Intervino también en la corrección de pruebas de la octava edición, trabajo por el que fue gratificado (Actas, 28 de septiembre de 1837) y remite listas de palabras hasta 1842 (Freixas 2019).

32 Por ejemplo, no parece haber cambios hasta el DRAE 1884 que reflejen aplicación de la división territorial por provincias de 1833 en las abreviaturas de notación geográfica, pese a que Javier de Burgos, su responsable, fue académico desde 1827 hasta su muerte en 1848 (Zamora 1999: 199-200). 
tada hacia la homogeneización de la variación existente desde época anterior ${ }^{33} \mathrm{y}$ otra, hacia la heterogeneidad que introduce una enmienda que nunca es sistemática y que se realiza por capas ${ }^{34}$. La ediciones estudiadas muestran una ampliación restringida y albergan una reorientación del diccionario usual con un amplio conjunto de supresiones en un intento de conseguir un diccionario "más manejable" con un apartamiento definitivo del Diccionario de autoridades y propician una progresiva conformación de la norma académica.

\section{REFERENCIAS BIBLIOGRÁFICAS}

Actas $=$ Real Academia Española: Actas (Libro 16, desde enero de 1790 hasta diciembre de 1795; Libro 17, desde enero de 1796 hasta 19 de junio de 1799; Libro 18, desde 24 de junio de 1800 hasta 12 de abril de 1808; Libro 19, desde abril de 1808 hasta 26 de febrero de 1818; Libro 20, desde 3 de marzo de 1818 hasta diciembre 1828; Libro 21, desde 8 de enero de 1829 hasta 15 de octubre de 1840; Libro 22, desde 22 de octubre de 1840 hasta 13 de octubre de 1853). Consultadas en el Archivo de la Real Academia Española.

Alvar Ezquerra, M. (2002 [1993]). "El diccionario de la Academia en sus prólogos". En De antiguos y nuevos diccionarios del español. Madrid: Arco/Libros, pp. 253-286 [antes en Lexicografía descriptiva. Barcelona: Bibliograf, 1993, pp. 215-239].

Álvarez de Miranda, P. (2003). "Vicente Salvá, editor y corrector del Diccionario de la Academia (1838 y 1841)". En Lexicografia y lexicología en Europa y América. Homenaje a Günther Haensch en su 80 aniversario. Madrid: Gredos, 99-114.

Álvarez de Miranda, P. (2007). "Panorama de la lexicografía española en el siglo XIX". En Dorta, J., C. Corrales y D. Corbella (eds.). Historiografía de la lingüística en el ámbito hispánico. Fundamentos epistemológicos y metodológicos. Madrid, Arco/Libros, pp. 329-356.

Álvarez de Miranda, P. (2011). En doscientas sesenta y tres ocasiones como esta. Discurso leído el día 5 de junio de 2011 en su recepción pública. Madrid: Real Academia Española.

Anglada, E. y M. Bargalló (1992). "Principios de lexicografía moderna en diccionarios del siglo XIX". En Ariza, M. et alii (eds.). Actas del II Congreso Internacional de Historia de la Lengua Española. Madrid: Pabellón de España, vol. I, pp. 955-962.

Azorín, D. (2000). Los diccionarios del español en su perspectiva histórica. Alicante: Publicaciones de la Universidad de Alicante.

Azorín, D. (2003). "Un proyecto original en la lexicografía española del siglo XIX: El Nuevo diccionario de la lengua castellana (1846) de Vicente Salvá". En Lexicografía y lexicología en Europa y América. Homenaje a Günther Haensch en su 80 aniversario. Madrid: Gredos, pp. 115-131.

Azorín, D. (2007a). "Salvá y la Academia Española: ¿Dos maneras de concebir el diccionario de la lengua?", Abhandlungen zur Sprache und Literature, 168, pp. 17-32.

Azorín, D. (2007b). La lexicografía monolingüe no académica en el siglo XIX. Liceus.com, 22 pp.

Azorín, D. (2012). "Contribución a la historia de los términos en los diccionarios generales del español: Salvá y la Academia Española ante el problema de los tecnicismos". En Rodríguez, F. (ed.). Estudios de lingüística española. Homenaje a Manuel Seco. Alicante: Publicaciones de la Univ. de Alicante, pp. 91-118.

Azorín, D. (2017). "L'attitude a l'égard des néologismes dans la trajectoire du dictionnaire académique. Un conflit entre la norme et l'usage", Cahiers de Lexicologie: Revue Internationale de Lexicologie et Lexicographie, 110, pp. 95-113.

33 El proceso de enmienda de las cuatro primeras ediciones (DRAE 1780-1803) es una muestra de ello. Buen ejemplo se encuentra en Jiménez Ríos 2019.

34 Se perciben estas dos tendencias, por ejemplo, en el análisis microscópico de los patronímicos (Carriet 2019) o en la conservación de otras muchas variantes antiguas. 
Azorín, D. (2018a). “El léxico con marcación estilística”. En Clavería, G. y M. Freixas (coords.), pp. 427-458.

Azorín, D. (2018b). "Salvá y la Academia española frente al tratamiento lexicográfico de los arcaísmos léxicos", Revista de Filología de la Universidad de La Laguna, 36, pp. 49-83.

Azorín, D. y R. Baquero (1994-1995). "De la teoría a la práctica lexicográfica: el Nuevo Diccionario de la lengua Castellana de Vicente Salvá", ELUA, 10, pp. 9-20.

Azorín, D.; J. M. Blecua; M. á. Blanco; C. Buenafuentes; G. Clavería; S. Huertas; M. Freixas; E. Jiménez Ríos; C. Julià; L. Muñoz; A. Paz; M. Prat; M. Raab; S. Varela; J. Torruella (2017). "Historia interna del Diccionario de la lengua castellana de la Real Academia Española en el siglo XIX (1817-1852)". En I. Sariego et alii (eds.). El diccionario en la encrucijada: de la sintaxis y la cultura al desafio digital. Santander: Escuela Universitaria de Turismo de Altamira-Asociación Española de Lexicografía Hispánica, pp. 151-172.

Azorín, D. y M. a A. Martínez (1988-1989). "El acento en la lingüística española del siglo XIX: aspectos del desarrollo de una teoría", ELUA, 5, 83-91.

Bahamonde, Á. y J. A. Martínez (1994). Historia de España. Siglo XIX. Madrid: Cátedra.

Battaner, M. ${ }^{a}$ P. (2008). "La Real Academia Española en las Cortes de Cádiz (1810-1814)", Boletín de la Real Academia Española, 88, pp. 5-32.

Blanco, M. Á. (2018). "El contexto del diccionario: los códigos académicos vigentes en 1817”. En Clavería, G. y M. Freixas (coords.), pp. 57-63.

Blanco, M. Á., G. Clavería y E. Jiménez Ríos (2018). "Fuentes lexicográficas y estudio del léxico: el Diccionario de la lengua castellana de la Real Academia Española (1817-1852)". En Corbella, D., A. Fajardo y J. Langenbacher (eds.). Historia del léxico español y humanidades digitales. Frankfurt: Peter Lang, pp. 449-475.

Blanco, M. Á. y Clavería, G. (2019). "Y así se dice: los ejemplos y las notas de uso en los diccionarios académicos (1726-1852)", ELUA, anexo V.

Blecua, J. M. (2017). "El diccionario como instrumento cultural de una lengua". En I. Sariego et alii (eds.). El diccionario en la encrucijada: de la sintaxis y la cultura al desafio digital. Santander: Escuela Universitaria de Turismo de Altamira-Asociación Española de Lexicografía Hispánica, pp. 51-63.

Buenafuentes, C. (2018). “Los criterios de lematización: las formas complejas”. En Clavería, G. y M. Freixas (coords.), pp. 115-136.

Buenafuentes, C. (2019). "La décima edición del Diccionario de la lengua castellana de la RAE (1852): el aumento y la supresión de voces", ELUA, anexo V.

Bueno, A. M. a (1995). La lexicografía monolingüe no académica del Siglo XIX. Tesis de doctorado dirigida por el Dr. M. Alvar Ezquerra, Universidad de Málaga.

Carr, R. (1988). España 1808-1975. Barcelona: Ariel, 4. ${ }^{\text {a }}$ edición.

Carriet, E. (2017). "La séptima edición del diccionario académico (DRAE 1832)", Revista de Lexicografía, 23, 39-65.

Carriet, E. (2019). "Los nombres patronímicos en la lexicografía académica", ELUA, anexo V.

Carriscondo, F. M. (en prensa). "Los episodios doceañistas y la incorporación de andalucismos al DRAE (1817)", Revue Romane, 54/1.

Carriscondo, F. M. (2017). Palabras que cambiaron (en) la historia [lexicología y lexicografía]. Gijón: Ediciones Trea.

Chaffee-Sorace, D. (1988). Gongora's poetic textual tradition. An analysis of selected variants, versions and imitations of his shorter poems. London: Tamesis.

Clavería, G. (2007). "Historia del léxico en los diccionarios: la deuda del Diccionario de la lengua castellana de la Real Academia Española con los diccionarios de M. Núñez de Taboada", Revista de Historia de la Lengua Española, 2, pp. 3-27.

Clavería, G. (2016). De vacunar a dictaminar. La lexicografía académica decimonónica y el neologismo. Madrid: Iberoamericana/Vervuert. 
Clavería, G. (2017). "El neologismo en diacronía (siglos XVIII y XIX)”. En Sánchez Ibáñez, M. et alii (eds.). La renovación léxica en las lenguas románicas. Proyectos y perspectivas. Murcia: Ediciones de la Universidad de Murcia, pp. 9-23.

Clavería, G. (2018a). "La quinta edición del Diccionario de la lengua castellana (1817) de la Real Academia Española al microscopio". En Clavería, G. y M. Freixas (coords.), pp. 15-55.

Clavería, G. (2018b). "Préstamos y adaptación en el español moderno". En Enguita, J. M. a et alii. Actas del X Congreso Internacional de Historia de la Lengua Española. Zaragoza: Institución Fernando el Católico, vol. I, pp. 1419-1453.

Clavería, G. (en prensa 1). "El Diccionario de la lengua castellana (1817-1832) y la propuesta decimonónica de diccionario manual", Boletín de la Real Academia Española, tomo 100, cuaderno 322.

Clavería, G. (en prensa 2). "América en el Diccionario de la lengua castellana de la Real Academia Española (1817-1852)”. Actas del XI Congreso Internacional de Historia de la Lengua Española (Lima, 6-10 agosto 2018).

Clavería, G. y M. Freixas (2015). "La quinta edición del Diccionario de la lengua castellana de la Real Academia Española (1817): el aumento de voces”. En García Martín, J. M. a (ed.), Actas del IX Congreso Internacional de Historia de la Lengua Española. Madrid/Frankfurt: Iberoamericana/ Vervuert, vol. II: pp. 1309-1326.

Clavería, G. y A. Paz (2018). "El discurso científico en la definición lexicográfica académica (DRAE 1817-1852)”. En Álvarez, X. A. et alii (eds.). Nuevas perspectivas en la diacronía de las lenguas de especialidad. Alcalá de Henares: Servicio de Publicaciones de la Universidad de Alcalá, pp. 69-85.

Clavería, G. y M. Freixas (coords.) (2018a). El diccionario de la Academia en el siglo XIX: la quinta edición (1817) al microscopio. Madrid: Arco/Libros.

Clavería, G. y M. Freixas (2018b). "El Nuevo tesoro lexicográfico de la lengua española: un museo lexicográfico como base de datos", Cuadernos del Instituto Historia de la Lengua, 11, pp. 117-138.

Clavería, G., M. Freixas y J. Torruella (2019). "Historia interna del Diccionario de la lengua castellana de la Real Academia Española en el siglo XIX (1817-1852): el léxico especializado". En Garriga, C. et alii (eds.), Estudios de lengua y ciencia. A Coruña: Univ. da Coruña, pp. 193-212.

Cotarelo y Mori, E. (1928). Discurso acerca de las obras publicadas por la Real Academia Española: leído en la junta pública de 7 de octubre de 1928 por Emilio Cotarelo y Mori, con ocasión de celebrar la "Fiesta del Libro" e inaugurar una exposición de las referidas obras. Madrid: Real Academia Española.

DECH = Corominas, J. y J. A. Pascual (1980-1991). Diccionario crítico etimológico castellano e hispánico. 6 vols. Madrid: Gredos; ed. en CD-ROM, Madrid: Gredos, 2012.

Esparza, M. Á. (1999). "La lexicografía monolingüe española del siglo XIX: un conflicto de paradigmas", Romanistik in Geschichte und Gegenwart 5/1, pp. 49-65.

Ferrer del Río, A. (1870 [1860]). Reseña histórica de la fundación, progresos y vicisitudes de la Real Academia Española, Memorias de la Academia Española. Madrid: Imprenta y Estereotipia de M. Rivadeneyra, pp. 176-196.

Fontana, J. (1971). La quiebra de la monarquía absoluta 1814-1820. (La crisis del Antiguo régimen en España). Barcelona: Ariel.

Fontana J., y R. Villares (dirs.) (2007). La época del liberalismo. Barcelona: Crítica/Marcial Pons.

Freixas, M. (2010). Planta y método del Diccionario de Autoridades. Orígenes del método lexicográfico de la Real Academia Española (1713-1739). A Coruña: Univ. da Coruña.

Freixas, M. (2018). "La definición y la descripción”. En Clavería, G. y M. Freixas (coords.), pp. 139-173.

Freixas, M. (2019). "La novena edición del diccionario académico (DRAE 1843)", ELUA, anexo V.

Freixas, M. y G. Clavería (2018). "Los criterios de lematización: los lemas simples y los lemas múltiples”. En Clavería, G. y M. Freixas (coords.), pp. 93-102. 
Fries, D. (1989). "Limpia, fija y da esplendor”. La Real Academia Española ante el uso de la lengua (1713-1973). Madrid: Sociedad General Española de Librería.

Fusi, J. P., y Palafox, J. (1997). España: 1808-1996. El desafio de la modernidad. Madrid: Espasa.

García de la Concha, V. (2014). La Real Academia Española. Vida e Historia. Barcelona: Espasa.

García Platero, J. M. (2003). "La lexicografía no académica en los siglos XVIII y XIX". En A. M." Medina (coord.). Lexicografía española. Barcelona: Ariel Lingüística, 263-306.

Garriga, C. (2018). "Las voces de la química". En Clavería, G. y M. Freixas (coords), pp. 313-337.

Garriga, C. (2019). "Ciencia, técnica y diccionario: incubando revoluciones", ELUA, anexo V.

Gómez de Enterría, J. (2018). "Las voces de ciencias naturales y áreas afines”. En Clavería, G. y M. Freixas (coords.), pp. 275-311.

Gutiérrez Cuadrado, J. (1987). "La sustitución del latín por el romance en la Universidad española del siglo XVIII". Universidades españolas y americanas. Valencia: Generalitat Valenciana, pp. 237-252.

Gutiérrez Cuadrado, J. (1988). "El latín sustituido por el castellano en la Universidad española (siglos XVIII-XIX)". En Ariza, M. et alii (eds.). Actas del I Congreso Internacional de Historia de la Lengua Española. Madrid: Arco/Libros, vol. II, pp. 1205-1213.

Gutiérrez Cuadrado, J. (2001-2002). "El nuevo rumbo de la vigésima segunda edición (2001) del Diccionario de la lengua española de la Real Academia", Revista de Lexicografía, VIII, pp. 297-319.

Jiménez Ríos, E. (2001). Variación léxica y diccionario: los arcaísmos en el diccionario de la Academia. Madrid: Iberoamericana.

Jiménez Ríos, E. (2013). La crítica lexicográfica y el Diccionario de la Real Academia Española: obras y autores contra el Diccionario. A Coruña: Univ. da Coruña.

Jiménez Ríos, E. (2017a). "Confluencia de arcaísmos en el DRAE”, Iberoromania, 86, pp. 259-276.

Jiménez Ríos, E. (2017b). "Voces de 'raro uso' en diccionarios del español (a propósito de los cambios en la 5. a edición del DRAE)", Archivum. Revista de la Facultad de Filología de la Universidad de Oviedo, LXVII, pp. 185-218.

Jiménez Ríos, E. (2018a). "Cambio de orientación en la lexicografía de la Real Academia Española a propósito de los arcaísmos en el DRAE de 1822", Orillas, Rivista d'Ispanistica, 7, pp. 309-328.

Jiménez Ríos, E. (2018b). "El diccionario, fuente para la historia del léxico: la supresión de arcaísmos gráficos en la sexta edición del Diccionario de la lengua castellana de la Real Academia Española (1822)", Boletín de Filología de la Universidad de Chile (BFUCh), LIII/1, pp. 131-168.

Jiménez Ríos, E. (2018c). "El léxico con marcación diacrónica". En Clavería, G. y M. Freixas (coords.), pp. 399-426.

Jiménez Ríos, E. (2019). "Participio pasivo y arcaísmo en el DRAE (ediciones de 1822 y 1832)", $E L U A$, anexo $\mathrm{V}$.

Jiménez Ríos, E. (2018d). "La revisión de arcaísmos en el DRAE en la primera mitad del siglo XIX", Estudios humanísticos. Filología, 40.

Jiménez Ríos, E. y G. Clavería (2018). "Las correspondencias latinas”. En Clavería, G. y M. Freixas (coords.), pp. 495-527.

Julià, C. (2019). "Voces y acepciones nuevas en el DRAE 1837", ELUA, anexo V.

Lázaro, F. (1949 [1985]). Las ideas lingüisticas en España durante el siglo XVIII. Barcelona: Crítica. Lemateca del DRAE: <http://draesxix.wixsite.com/draesxix/lemateca>.

Lliteras, M., y A. Hernández (2008). "La neología en la gramática y el diccionario del siglo XIX", Quaderns de Filologia. Estudis lingüistics, XIII, 231-250.

Lombardini, H. E. (2011). "Prólogos de los DRAE e ideología subyacente". En San Vicente, F. et alii (eds.). Ideolex. Estudios de lexicografía e ideología. Monza: Polimetrica, 305-327.

Lucena, M. (1992). Historia de Iberoamérica, vol. III: Historia contemporánea. Madrid: Cátedra.

Mapa de diccionarios: Instituto de Investigación Rafael Lapesa - Real Academia Española. Mapa de diccionarios. $<$ http://www.rae.es $>$. 
Martínez González, A. (2015). "Historia de una emigración: fr. néologique, 1726, esp. neológico, DRAE 1843”. En Bruley, C. y J. Suso (eds.). La terminología gramatical del español y del francés. Emergencias y trasposiciones, traducciones y contextualizaciones/La terminologie grammaticale de l'espagnol et du français: émergences et transpositions, traductions et contextualisations. Frankfurt-Berlin-Bern-Bruxelles-New York-Oxford-Wien: Peter Lang, pp. 311-336.

Matilla, A. (1982). "Para la historia del Diccionario", Boletín de la Real Academia Española, 62, pp. 441-443.

Merino, J. M.. (2013). "De afrancesados a patriotas en la Real Academia Española". En Sánchez Ron, J. M. y C. Iglesias (coords.). La lengua y la palabra: trescientos años de la Real Academia Española. Madrid: Real Academia Española, pp. 81-88.

Monlau, P. F. (1863): Del arcaísmo y el neologismo ¿Cuándo se debe considerar fijada una lengua? Discurso escrito por el Ilmo. Sr. D. Pedro Felipe Monlau, individuo de número de la Real Academia Española y leído en la junta pública que para solemnizar el aniversario de su fundación celebró dicho cuerpo literario, en cumplimiento del art. XXV de sus estatutos, el día 27 de septiembre de 1863. Madrid: Imprenta Nacional.

Muñoz, L. (2018). "La sinonimia y las remisiones”. En Clavería, G. y M. Freixas (coords.), pp. 203221.

Muñoz, L. (2019). "El léxico especializado en la 9. a edición del DRAE (1843)", ELUA, anexo V.

NTLLE = ReAl ACAdEMia Española (2001). Nuevo Tesoro Lexicográfico de la Lengua Española. Madrid: Espasa, edición en DVD. [También en $<$ http://ntlle.rae.es $>$ ].

Núñez de Taboada, M. (1812). Dictionnaire français-espagnol et espagnol-français. Paris: Librería de Seguin.

Núñez de Taboada, M. (1823). Nouveau dictionnaire de poche. Paris: Librería de Seguin.

Núñez de Taboada, M. (1825). Diccionario de la lengua castellana. Paris: Librería de Seguin.

Pascual Fernández, L. (2013). Diccionario de autoridades (2. ${ }^{a}$ ed.): técnica lexicográfica y lengua de la ciencia. Tesis doctoral dirigida por J. M. Blecua, Bellaterra: Universitat Autònoma de Barcelona (Facultad de Filosofía y Letras, Departamento de Filología Española), disponible en $<$ http://www.tdx.cat/bitstream/ handle/10803/125972/mlpflde1.pdf?sequence=1>.

Paz, A. (2018). "La información lexicográfica de las formas complejas". En Clavería, G. y M. Freixas (coords.), pp. 223-252.

Petrecca, F. (1992). "Taxonomía científica y discurso lexicográfico", Boletín de la Real Academia Española, 72, pp. 251-267.

Prat, M. (2018). "Los criterios de lematización: los lemas múltiples y la sufijación apreciativa". En Clavería, G. y M. Freixas (coords.), pp. 103-113.

Puche, M. Á. (2019). "El DRAE a través de la prensa española (1817-1852)", ELUA, anexo V.

Quilis Merín, M. (2016). "La lexicografía española del siglo XIX: una perspectiva historiográfica". En La historiografía lingüística como paradigma de investigación. Madrid: Visor Libros, pp. 45-78

Raab, M. (2019). "Ideología y diccionarios: acerca de lo nacional y lo liberal en la lexicografía del siglo XIX", ELUA, anexo V.

Roca de Togores, M. [Marqués de Molins] (1870). "Reseña histórica de la Academia Española". En Memorias de la Academia Española I. Madrid: Imprenta y esterotipia de M. Rivadeneyra, pp. 7-128.

Rosenblat, Á. (1951). "Las ideas ortográficas de Bello". En Bello, A., Obras completas, V, Estudios gramaticales. Caracas: Ediciones del Ministerio de Educación, pp. IX-CXXXVIII.

San Vicente, F. (1996). "Filología”. En Aguilar Piñal, F. (dir.). Historia literaria de España en el siglo XVIII. Madrid: Editorial Trotta, CSIC, pp. 593-669.

San Vicente, F. (2010). "Autor, norma y uso en los prólogos del DRAE (1780-2001)”. En Chierichetti, L. y G. Garofalo (eds.). Lengua y Derecho: líneas de investigación interdisciplinaria. Berna: Peter Lang.

San Vicente, F. y H. Lombardini (2012a). "Hiperestructura del DRAE (1780-2001)". En Rio-Torto, G. (ed.). Léxico de la ciencia: tradición y modernidad. Muenchen: Lincom Europa, pp. 70-96. 
San Vicente, F. y H. Lombardini (2012b). "Prólogos del DRAE (1780-2001): cánones formales y de contenido". En Nomdedeu, A. et alii (eds.), Avances de lexicografía hispánica. Tarragona: Universitat Rovira i Virgili, pp. 479-493.

Seco, M. (1987). "El nacimiento de la lexicografía moderna no académica". En Estudios de lexicografía española. Madrid: Paraninfo, pp. 129-151.

Seco, M. (1994). "Menéndez Pidal y el Diccionario manual de la Academia”. En Sánchez Lobato, J. et alii (coords.). Sin fronteras: Homenaje a María Josefa Canellada. Madrid: Universidad Complutense, pp. 539-547.

Terrón, N. (2017). "Gramática y diccionario: aproximación al tratamiento de los usos pronominales de los verbos en la lexicografia académica". En Sariego, I. et alii (eds.). El diccionario en la encrucijada: de la sintaxis y la cultura al desafio digital. Santander: Escuela Universitaria de Turismo de Altamira-Asociación Española de Lexicografía Hispánica, pp. 917-936.

Terrón, N. (2018a). "Historia de la lengua y lexicografía: el aumento de voces en la 6. a edición del Diccionario de la Academia (1822)". En Enguita, J. M. a et alii (eds.). Actas del X Congreso Internacional de Historia de la Lengua Española. Zaragoza: Institución Fernando el Católico.

Terrón, N. (2018b). "La regularización ortográfica". En Clavería, G. y M. Freixas (coords.), pp. 67-91.

Terrón, N., y Torruella, J. (2019a). "Estudio de la sexta edición del Diccionario de la lengua castellana de la Real Academia Española", ELUA, anexo V.

Terrón, N., y Torruella, J. (2019b). "La definición sinonímica en la sexta edición del Diccionario de la lengua castellana de la Real Academia Española”, Revista de Filología de la Universidad de la Laguna, 39, pp. 307-328.

Varela, S. (2018). "El léxico con marcación diatópica". En Clavería, G. y M. Freixas (coords.), pp. 459-480.

Zamora, A. (1999). Historia de la Real Academia Española. Madrid: Espasa. 